Article

\title{
Gender Differences in the Early Employment Outcomes of STEM Doctorates
}

\author{
Kimberlee A. Shauman \\ Department of Sociology, University of California, Davis, CA 95616, USA; kashauman@ucdavis.edu; \\ Tel.: +1-530-754-0773 \\ Academic Editors: Maria Charles and Sarah Thébaud \\ Received: 1 September 2016; Accepted: 15 February 2017; Published: 4 March 2017
}

\begin{abstract}
The representation of women among STEM doctorates has grown over the past decades but the underrepresentation of women in the STEM labor force persists. This paper examines the immediate post-degree employment outcomes of nine cohorts of STEM doctorates who attained their degrees between 1995 and 2013. The results reveal both progress toward gender equity and persistent inequities. Contrary to historical gender disparities, a small female advantage has emerged in the attainment of tenure-track faculty positions, women are increasingly less likely than men to enter postdoctoral positions, and the flow of STEM doctorates into business and industry, which was once male dominated, is now gender neutral. Among the doctorates who do not follow the doctorate-to-faculty career path, women are as likely as men to "stay in STEM," but less likely to attain research-oriented jobs. Gender segregation in occupational attainment and significant gender gaps in earnings, however, continue to be defining characteristics of the STEM labor force. The results show that the labor market disparities vary across STEM fields but are largely not attributable to the gendered impact of parenthood and dual-career marriage.
\end{abstract}

Keywords: gender; STEM; labor market; family; trends; segregation

\section{Introduction}

The representation of women among doctorates in science, technology, engineering and mathematical (STEM) fields has grown significantly over the past decades [1] but the underrepresentation of women in the STEM labor force persists [2]. Women with STEM doctorates are less likely than men to work in STEM occupations, and those who do are less likely to be employed in the most prestigious and well-paid positions in academia, government, business and industry $[3,4]$. The observed gender inequalities in the STEM labor force are generated by myriad influences and sorting processes operating continuously throughout the life course [3], but recent evidence points to the critical and long-term impacts of the immediate post-degree transitions. For example, a primary cause of the continued underrepresentation of women among recent cohorts of research university faculty is that women may be less likely than men to apply for faculty positions [4,5]. Identifying the extent, character and causes of gender differences in early employment transitions is therefore central to understanding gender differences in the STEM labor force and developing policies that support the optimal and equitable development of STEM talent.

In this paper, I present a detailed analysis of the immediate post-degree transitions of doctorates in STEM fields, using data from nine cohorts of doctorates from the 1995-2013 waves of the Survey of Doctorate Recipients (SDR). I focus on the transition to the labor market within two years of Ph.D. completion and examine gender differences in multiple employment outcomes that capture the full range of post-degree labor market experiences that may impact career development. This analysis is motivated by 4 research questions: 
- Are there gender differences in the immediate post-degree labor market outcomes of STEM doctorates?

- Which labor market outcomes have the greatest gender disparities?

- Have the observed gender disparities changed over time?

- Do the gender differences in labor market outcomes vary by STEM field, and are they associated with the doctorates' family characteristics?

This analysis is largely descriptive in that I identify where the labor market experiences of women and men differ and if those differences are correlated with a set of variables measuring the family characteristics of the STEM doctorates. By disaggregating the transition to the labor market and examining gender differences across multiple aspects of early employment, I provide a more nuanced assessment of the degree to which women are less likely to utilize their educational investments and to leave the STEM labor force. I focus on assessing the influence of family characteristics on gender differences in employment outcomes because prior research identifies parenthood and other family characteristics, e.g., dual-earner couple status, as having particularly negative effects on women's employment outcomes in the STEM fields. The demands of childbearing and of caring for young children appear to have a particularly negative influence on the likelihood that women will stay in STEM fields and attain career success on a par with their male colleagues $[3,6,7]$. Research has also identified employer behaviors, such as unconscious bias against women in general [8-10], and against mothers in particular [11], along with structural and cultural aspects of STEM workplaces [12] that operate on the demand-side to inhibit the career progress of women.

This study is designed to address four empirical limitations of prior research. First, analyses of gender differences in STEM tend to focus on single employment outcomes and to collapse all alternatives into a single comparison category. Such simplistic operationalizations of the transition process can identify neither the relative probability of competing employment outcomes nor the correlates of those outcomes. The employment outcome that has received the most attention is the attainment of a tenure-track job, and the focal question is: why are women not attaining/choosing academic jobs? Analyses addressing this question often use a dichotomous classification of employment outcomes, academic vs. non-academic positions, which obscures the heterogeneity among the alternatives to academic employment. When a clearly-defined outcome is contrasted with a heterogeneous aggregation of "other" outcomes, only the characteristics of the focal employment outcome and the influence of correlates associated with its achievement can be measured with accuracy. Studies that employ this strategy cannot adequately address why women choose non-academic jobs, what characteristics of non-academic jobs they attain, and how they fare in those jobs relative to men. Studies that focus on the academia-vs.-other dichotomy also reify the assumptions that employment in academia is the most desirable outcome and that other types of employment represent a "loss" at both the individual and institutional levels-individual women disproportionately "lose" in the competition for academic employment and the science pipeline "loses" women disproportionately. This assumption is further bolstered by a tendency for the research to focus on factors that might "push" women out of academia (e.g., chilly climate, incompatibility of academia with family formation, etc.) [13-15] and to neglect positive aspects of non-academic employment options that might "pull" women to other sectors of STEM employment.

Second, the study of differences in employment outcomes tends to ignore the dynamic and contingent nature of career development. Despite the universal adoption of the "pipeline" characterization of the science career trajectory, the study of gender differences in STEM is segmented into literatures that focus on distinct career stages but rarely examine the transitions between those stages [3]. The contingent nature of the successive stages of the career trajectory is acknowledged but not often incorporated into analyses. Research commonly compares the representation of women at prior stages in the trajectory to their representation at a subsequent stage without attending to the intervening transitions that condition the likelihood of the focal outcome. Yet inattention to intervening transitions may produce biased estimates of gender differences and misidentification of their causes. 
It is common, for example to compare the percent female among tenured faculty with the percent female among doctorates to assess the size of the gender gap in the tenure rates. The appropriate denominator for the calculation of gender differences in the tenure rate is a much-debated topic that hinges on the degree to which the transitions that intervene between degree attainment and achievement of tenure are acknowledged. Estimated gender differences in the rate of tenure attainment will vary from large to non-existent depending upon whether the denominator of the rate is all doctorates, doctorates who enter the labor force, doctorates who apply for tenure-track positions, or just the doctorates who attain a tenure-track position. Analyses of career outcomes that ignore the nested or conditioning effect of intervening transitions are unlikely to accurately represent the career-building process and, therefore, to identify the component processes that generate gender-specific outcomes.

Third, extant research has tended to ignore the heterogeneity within science fields and across the labor market for doctorate-level scientists and engineers. The distribution of doctorates across the STEM fields is significantly segregated by gender and since post-doctorate career pathways are also field-specific, gender segregation will yield significant aggregate-level gender differences in employment patterns. However, there is ample evidence of significant gender differences in academic employment, rates of promotion to tenure, salary and other employment outcomes among doctorates in the same field [16-18]. These within-field gender differences in the career paths of doctoral scientists may be driven by influences that are unique to specific STEM fields. Analyses that aggregate science fields therefore risk obscuring or misrepresenting the magnitude of the gender differences that exist, and attributing gender differences in educational and occupational experiences in blanket fashion when they apply in only specific fields.

Fourth, prior research has measured "persistence in STEM" in a narrow way that may underestimate the degree to which women apply their STEM education in the labor market. Attaining a tenure-track faculty position at a research-intensive university is often characterized as the ideal labor market application of a STEM doctorate because such employment fully utilizes the educational capital the STEM Ph.D. represents. Other types of employment vary in the degree to which they utilize doctoral-level training in a STEM field and are part of "the STEM pipeline." Some jobs will rival the research university faculty position in their demand for specialized knowledge and skills, some will demand only some of the specialized training gained in the pursuit of a STEM doctorate, while the performance of others will demand none of that training. Identifying the degree to which the STEM doctorate is utilized in various occupational outcomes is therefore at the heart of our ability to reliably identify gender differences in the utilization of STEM education and participation in the science labor market. Prior research on gender differences in the "science pipeline," has relied on a researcher-imposed operationalization of educational utilization [3], by which researchers classify a set of occupations as those that comprise the STEM labor market, and employment in one of these occupations is defined as the utilization of STEM education. I propose and apply a more data-driven approach to identifying STEM-related employment for the analysis presented in this paper. See Appendix B for a discussion of the approach and Section 2.1.2 for a description of how it is applied in this study.

To address the limitations of prior research, I consider post-doctorate labor market entry as a set of contingent transitions that result in employment in a range of academic and non-academic settings. Figure 1 presents the conceptualization of the post-doctorate transition to the labor market that guides this analysis. I analyze gender differences in four nested employment outcomes and in the salary the doctorates earn 2 years after completing their degrees. The conditional nature of the labor market outcomes is reflected in the analytical design in that preceding states define the population at risk of subsequent outcomes. 


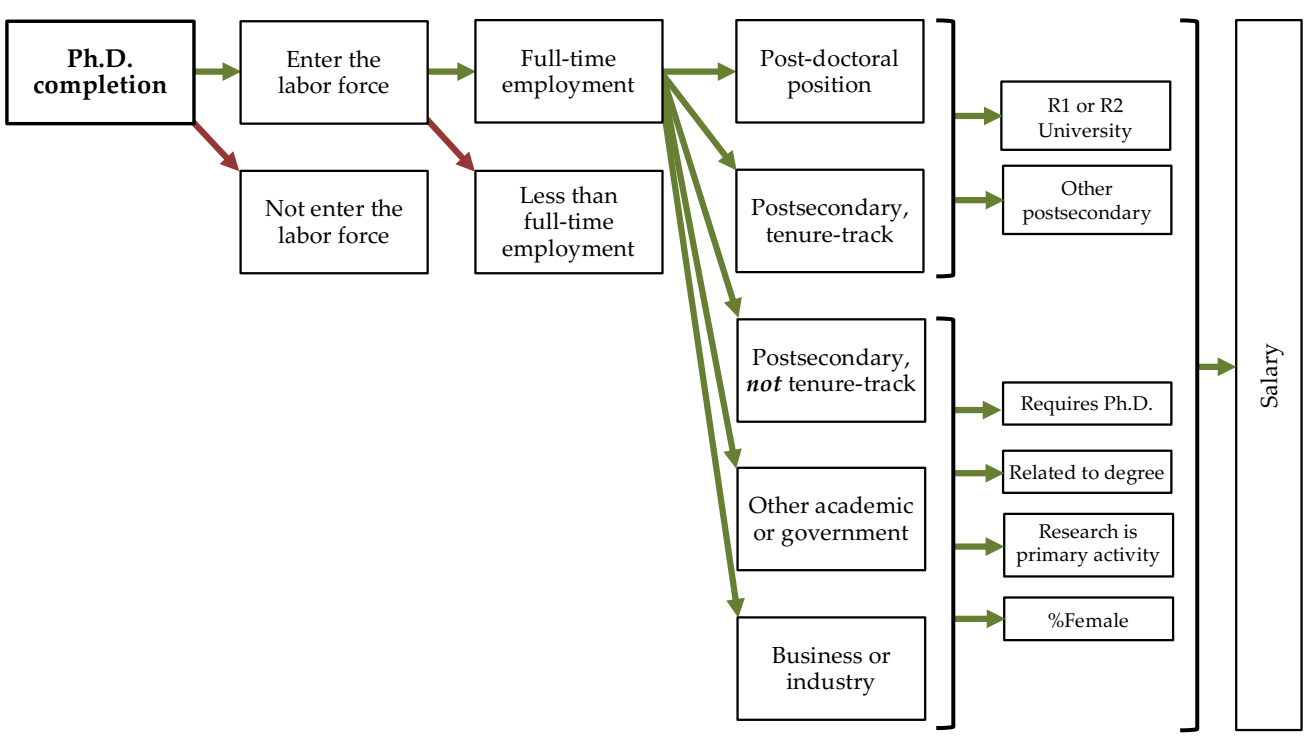

Figure 1. Schematic representation of post-doctoral employment transitions and outcomes.

Among the full population of STEM doctorates, all possible employment outcomes depend on whether a doctorate enters the labor market. Doctorates who enter the labor market and gain employment ${ }^{1}$ may work full or part time, and since part-time jobs are not equally distributed across the labor market, the degree of labor force attachment has implications for the types of jobs doctorates may attain. Gender differences in part-time employment may therefore help explain other disparities in STEM labor force outcomes. Among full-time workers, STEM doctorates may enter a broad range of occupations which I classify as belonging to five discrete employment sectors: (1) postdoctoral positions; (2) tenure-track faculty positions in postsecondary educational institutions; (3) non-tenure-track faculty positions in postsecondary educational institutions; (4) other academic positions, including those in elementary and secondary school, and government positions; and (5) positions in business or industry. Although each of these categories offers opportunities to utilize the educational investments that the STEM doctorates have made by doing work that is related to their doctoral field and training, there is significant between-category variation in the types of jobs they offer. The five categories also differ in the degree to which they capture a homogeneous set of jobs: the first and second categories are the most homogeneous, whereas the "other academic or government" and "business or industry" sectors are quite heterogeneous. I therefore distinguish different types of employment outcomes within each of these sectors. In light of the persistent underrepresentation of women among the faculties at research-intensive universities (those classified as R1 and R2 doctoral-granting institutions on the Carnegie Classification), and because the attainment of a postdoctoral position, especially at a research-intensive university, has become a necessary prerequisite a faculty position $[19,20]$, I assess the likelihood of attaining employment at such institutions among the STEM doctorates who enter postdoctoral positions and tenure-track faculty positions. For doctorates entering the other three employment sectors, I examine the likelihood that they attain jobs where their educational investment is utilized-indicated by the degree to which the job requires a Ph.D., is closely related to their degree field, and research is a primary job activity. I also assess the degree to which the transition into these employment sectors is marked by gendered sorting by testing the association between the doctorates' gender and the gender-type of the occupations they enter, as measured by the percentage of females among incumbents.

1 Unemployment is negligible in the data, so labor force participation and employment are essentially equivalent. 
The relationships between the employment outcomes specified in Figure 1 are more complex and recursive than depicted, but modeling the transition to the labor market as a discrete set of steps has a number of advantages. First, it reflects the contingent nature of the transition to the labor force by identifying the successively selective segments of the population of doctorates at risk of each type of outcome. Second, this approach to defining the population at risk of each outcome yields relatively conservative estimates of the gender gaps that characterize each and allows identification of where the gender gaps are greatest. Third, by considering both academic and non-academic employment outcomes, as well as those that are related and unrelated to doctoral degrees in STEM fields, this approach provides a more complete assessment of the career paths followed by STEM doctorates. It therefore can test the perception that women are disproportionately "lost" from science, and achieve a more nuanced assessment of how STEM doctorates utilize their educational investments.

I note that the conceptualization presented in Figure 1 includes two outcomes that are characterized as terminal (indicated by red arrows): the transition out of the labor force and part-time employment. These transitions do not, in fact, preclude full labor market participation but gaps in labor force participation and full employment do impact job placement, promotion rates and earnings trajectories [21]. However, I bracket such questions about gender differences in the experience and impact of these labor market states from this analysis.

\section{Materials and Methods}

\subsection{Data}

This analysis uses data from two sources: the 1995, 1997, 1999, 2001, 2003, 2006, 2008, 2010, and 2013 waves of the Survey of Doctorate Recipients (SDR) [22] and the O*NET Occupational Information Network Database (O*NET) [23]. The SDR is a longitudinal study of individuals who obtained a doctoral degree in a science, engineering or health field from a postsecondary institution in the U.S. The biennial survey conducted by the National Center for Science and Engineering Statistics collects information about the doctorates' demographic characteristics, educational background, employment situations, and other measures of career achievement. The SDR includes detailed classifications of both Ph.D. degree field and occupation, so it supports the identification of specific education-occupation transitions.

The SDR data supply both the analytical sample of recent STEM doctorates used to measure gender differences in the transition to the labor market and a sample used to operationalize three measures of job characteristics that are specific to the population of doctorates (see description in Section 2.1.2). Although the SDR is a longitudinal dataset, the sample used for this analysis is drawn from the "new cohort" of doctorates that is added at each new wave of the SDR. The analytical sample is therefore an aggregation of single-year, cross-sectional data snapshots of each new cohort of STEM doctorates, i.e., it does not incorporate the longitudinal nature of the data. Each new cohort includes approximately 5000 doctoral recipients who received their degree within two years of the survey date. ${ }^{2}$ The analytical sample therefore includes a total of 18,687 doctorates, 12,953 men and 5,734 women aged 25 to 50 who had attained a doctoral degree within the 2 years preceding the survey, i.e., degrees earned in the years 1993 through 2011, who provided complete information about their employment status and occupation.

The occupation-level characteristics are aggregated from a larger 'operationalization sample' that includes all respondents from the SDR "older cohorts" who meet the following criteria: they are aged 25 to 50 years; they had attained a STEM doctoral degree 3 to 13 years prior to the survey date; they reported being employed and working 35 or more hours per week at the time of the survey; and they provided complete responses about their doctorate field, their occupation, and to a set of survey items 
soliciting their subjective assessment of the extent to which their job is related to their degree field and if research is a primary activity of their job. The operationalization sample drawn using these selection criteria consists of 63,962 individuals (47,700 men and 16,262 women) who earned their degree in the years 1982 to 2010. This sample includes multiple observations of individual doctorates and thereby provides the large sample required to generate reliable measures of occupational characteristics by degree field and year. I emphasize, however, that the operationalization sample is exclusive of the analytical sample of sample of STEM doctorates, so the measures of education-occupation relatedness are exogenous to the behavior of the STEM doctorates included in the analytic sample.

The O*NET data includes detailed information about the characteristics, requirements and activities of a broad range of occupational and worker attributes for jobs classified according to the Standard Occupational Classification (SOC) system that are gathered from on-going representative surveys of job incumbents [24]. I use these data to operationalize one of the job-level characteristics included in this analysis: the level of education required to perform a job (described in Section 2.1.2).

\subsubsection{Individual-Level Variables Measuring the Characteristics of STEM Doctorates}

Table 1 presents the distribution of the analytical sample of STEM doctorates by the variables measuring their Ph.D. degree field, demographic characteristics, educational background, and family characteristics. I define STEM fields as including engineering and all mathematical, biological and physical sciences. The field in which each respondent earned his/her degree is coded per a 4-category classification that aggregates the categories of the more detailed major field coding scheme available in the SDR data (Table A1 lists the 4-category aggregation of 15 detailed codes). The biological sciences are the most common fields of specialization among the STEM doctorates, accounting for almost 37 percent of all doctorates, followed by engineering which accounts for about 30 percent and the physical sciences at 22 percent. Math and computer science account for the remaining 11 percent of STEM doctorates. Table 1 reflects the well-documented patterns of sex segregation among STEM fields: women are overrepresented among doctorates in the biological sciences but are underrepresented in all other STEM fields. Women are especially scarce among engineering doctorates where they account for only 18 percent of all doctorates awarded from 1995 to 2013.

This analysis of employment outcomes among STEM doctorates includes controls for age, an indicator of U.S. citizenship, and a 5-category classification of race/ethnicity. Educational background is controlled with two variables: a continuous indicator of the number of years between bachelor's and doctorate degree and a categorical indicator of the Carnegie classification of the doctorates' degree-granting institution. The gender gap in time-to-doctorate may measure an aspect of human capital that is associated with employment outcomes [3], and the influence of the "quality" or prestige of the doctorate-granting institution on the employment outcomes of academic scientists is well-documented [25,26]. Women doctorates take fewer years on average between their bachelor's and doctoral degrees than do men, and although women are not underrepresented among doctorates from R1 universities, they are marginally underrepresented among doctorates from R2 universities. I measure the doctorates' family characteristics with a series of dummy variables indicating the presence of children of aged under 2 years, 2-5 years, and 6-17 years, and a categorical indicator of the presence and employment status of a spouse. Male and female doctorates differ on all the family characteristics measured. Women are less likely than men to be married, more likely to be childless, and more likely to have spouses who work either part or full time. 
Table 1. Sample means for variables measuring degree field, demographic characteristics, educational background, and family structure for all recent doctorates, by gender.

\begin{tabular}{|c|c|c|c|c|c|}
\hline & Total & Males & Females & & $\%$ Female \\
\hline Sample size $(n)$ & 18,687 & 12,953 & 5734 & & 30.684 \\
\hline \multicolumn{6}{|l|}{ Degree field } \\
\hline Mathematical \& computer sciences & 0.113 & 0.123 & 0.089 & $* * *$ & 24.186 \\
\hline Biological sciences & 0.368 & 0.290 & 0.544 & $* * *$ & 45.316 \\
\hline Physical sciences & 0.223 & 0.237 & 0.193 & $* * *$ & 26.528 \\
\hline Engineering & 0.296 & 0.350 & 0.175 & $* * *$ & 18.092 \\
\hline \multicolumn{6}{|l|}{ Demographic characteristics } \\
\hline Age & $\begin{array}{l}33.438 \\
(4.886)\end{array}$ & $\begin{array}{l}33.552 \\
(4.884)\end{array}$ & $\begin{array}{l}33.181 \\
(4.881)\end{array}$ & $* * *$ & \\
\hline U.S. citizen & 0.593 & 0.568 & 0.650 & $* * *$ & \\
\hline \multicolumn{6}{|l|}{ Race } \\
\hline White, non-Hispanic & 0.574 & 0.569 & 0.585 & * & \\
\hline Black, non-Hispanic & 0.029 & 0.026 & 0.036 & $* * *$ & \\
\hline Asian or Pacific Islander, non-Hispanic & 0.351 & 0.364 & 0.324 & $* * *$ & \\
\hline Hispanic & 0.037 & 0.034 & 0.044 & $* * *$ & \\
\hline Other, non-Hispanic & 0.008 & 0.007 & 0.010 & & \\
\hline \multicolumn{6}{|l|}{ Educational background } \\
\hline Years from BA to Ph.D. & $\begin{array}{r}9.544 \\
(3.785)\end{array}$ & $\begin{array}{r}9.617 \\
(3.808)\end{array}$ & $\begin{array}{l}9.380 \\
(3.727)\end{array}$ & $* * *$ & \\
\hline \multicolumn{6}{|c|}{ Carnegie classification of doctorate-granting institution } \\
\hline R1 University & 0.741 & 0.744 & 0.735 & & \\
\hline R2 University & 0.109 & 0.111 & 0.103 & + & \\
\hline Doctorate Granting & 0.098 & 0.099 & 0.096 & & \\
\hline Other & 0.052 & 0.045 & 0.067 & $* * *$ & \\
\hline \multicolumn{6}{|l|}{ Family Characteristics } \\
\hline \multicolumn{6}{|l|}{ Family structure at time of survey } \\
\hline No children & 0.629 & 0.604 & 0.685 & $* * *$ & \\
\hline Children aged $<2$ years & 0.188 & 0.200 & 0.163 & $* * *$ & \\
\hline Children aged $2-5$ years & 0.168 & 0.185 & 0.130 & $* * *$ & \\
\hline Children aged 6-17 years & 0.122 & 0.135 & 0.093 & $* * *$ & \\
\hline \multicolumn{6}{|l|}{ Marital status/Spouse's work status } \\
\hline Unmarried & 0.285 & 0.274 & 0.311 & $* * *$ & \\
\hline Spouse works full time & 0.423 & 0.352 & 0.581 & $* * *$ & \\
\hline Spouse works part time & 0.073 & 0.090 & 0.033 & $* * *$ & \\
\hline Spouse does not work & 0.219 & 0.283 & 0.075 & $* * *$ & \\
\hline
\end{tabular}

Notes: Sample means and standard deviations (in parentheses) are weighted to account for sampling design; $+p \leq 0.10,{ }^{*} p \leq 0.05,{ }^{* *} p \leq 0.01,{ }^{* * *} p \leq 0.001$, for two-tailed test of sex differences. Source: Author's calculations using data from the Survey of Doctorate Recipients [22], 1995-2013.

2.1.2. Occupation-Level Variables Measuring the Relationship between STEM Fields and Occupations

I create four occupation-level variables to measure occupational sex-typing and the extent to which an occupation is related to a STEM doctorate. See Appendix B for a full discussion of the approach used. The doctorate-occupation relatedness variables aim to quantify the degree to which an occupation requires doctorate-level education, demands research skills, and is substantively related to each degree field. All occupation-level variables are measured using the most detailed level of occupational classification (131 categories) available in the SDR. Table S1 presents the full list of occupational categories, along with the occupational distribution for both the analytical and operational samples of STEM doctorates from the SDR. The occupation-level variables are also allowed, when possible and appropriate, to vary by degree field (using the detailed classification) and survey year. The occupation-level variables are linked to the individual-level data by survey year, occupation, and degree-field. 


\section{Demand for Doctoral-Level Education}

The variable measuring the occupational requirement for doctoral-level education is generated using data from the O*NET 12.0-18.0 Databases. The O*NET survey asks respondents to specify the level of education, from a list that distinguishes 12 levels of certification and degree attainment, "that is required to perform their job" [24]. I operationalize the demand for doctoral-level education as the percent of $\mathrm{O}^{*} \mathrm{NET}$ respondents who specify that a doctoral or post-doctoral degree is required for performance of their job. I then aggregate the SOC-level information to the 131-category SDR occupational coding scheme and specify the mean of the percent reporting a requirement for doctoral-level education within the aggregated categories as the measure of occupational demand for doctoral-level education. This variable varies by occupation and year and ranges from 0 to 100 .

Occupation-Degree Field Relatedness and Demand for Research Skills

To measure the extent to which occupations are substantively related to degree fields and demand research skills, I use the SDR operationalization cohort data for two survey items that are included in all waves of the SDR survey. The first item reads, "To what extent was your work on your principal job held during the week of [survey reference date] related to your highest degree?" and respondents could choose "closely related," "somewhat related," or "not related." The second survey item is a dichotomous indicator of whether the respondent indicates that "basic research, applied research, development, or design" is either their primary or secondary work activities at their job. The variable measuring occupation-degree relatedness is operationalized as the percent of respondents, identified by each possible combination of the 15-category classification of degree field and the 131-category occupational classification who report that their occupation is "closely related" to their degree field. Similarly, the variable measuring occupational demand for research skills is defined as the percent of respondents identified by each field-occupation pairing who report that research was their primary or secondary work activity. All data are weighted prior to aggregation to account for the sampling design and calculated separately by survey year. The values of both variables range from 0 to 100 , and since small cell sizes can produce highly variable estimates with low reliability, each variable is coded to 0 for combinations of degree field and occupation that are experienced by fewer than 5 individuals within each survey year. These variables are linked to the individual-level data by the detailed (15-category) classification of degree field, occupation, and survey year.

Occupational Sex-Typing

I use the percent of females among the operational cohort of doctorates in each of the 131 occupational categories as a measure of the occupational sex-typing. ${ }^{3}$ This variable ranges from 0 to 100 and is calculated separately for each year. Including this variable in the analysis allows a test of the degree to which occupational attainment among STEM doctorates at the transition to the labor market follows (or departs from) established patterns of occupational segregation by gender.

\subsection{Methods}

To analyze gender differences in the labor market outcomes for STEM doctorates, I use regression models for categorical and linear dependent variables. The labor market outcomes that are operationalized as binary variables-labor market entry, full-time work versus less-than-full-time work, and employment at a R1/R2 versus all other postsecondary institutions-are analyzed with binary logit models. The analysis of employment sector, a nominal outcome with 5 categories, uses a multinomial logit. I use linear regression models to analyze gender differences in the doctorate-occupation

3 To generate reliable measures of the percent female in the observed occupations, I use the full sample of SDR respondents, regardless of degree field. The sample includes 95,244 individuals (57,934 men and 37,310 women). 
relatedness variables, occupational percent-female, and salary among the STEM doctorates employed full time. ${ }^{4}$ The focal independent variable in all models is FEMALE, an indicator of the doctorates' self-identified gender (FEMALE $=1$ for females) and each model includes an extensive set of covariates. The coefficient for FEMALE from each model estimates the average gender gap in labor market outcomes (controlling for all covariates), change over time in the gap, and variation in the gap by STEM field and by family structure.

\section{Results}

\subsection{Gender Differences in the Labor Market Outcomes of STEM Doctorates}

Figure 2 presents the probability of each labor force outcome depicted in Figure 1 separately by gender and illustrates how the early post-degree employment outcomes of STEM doctorates differ for women and men. These results address the first two research question: Are there gender differences in the early labor market outcomes of STEM doctorates? For which outcomes are the gender disparities greatest?

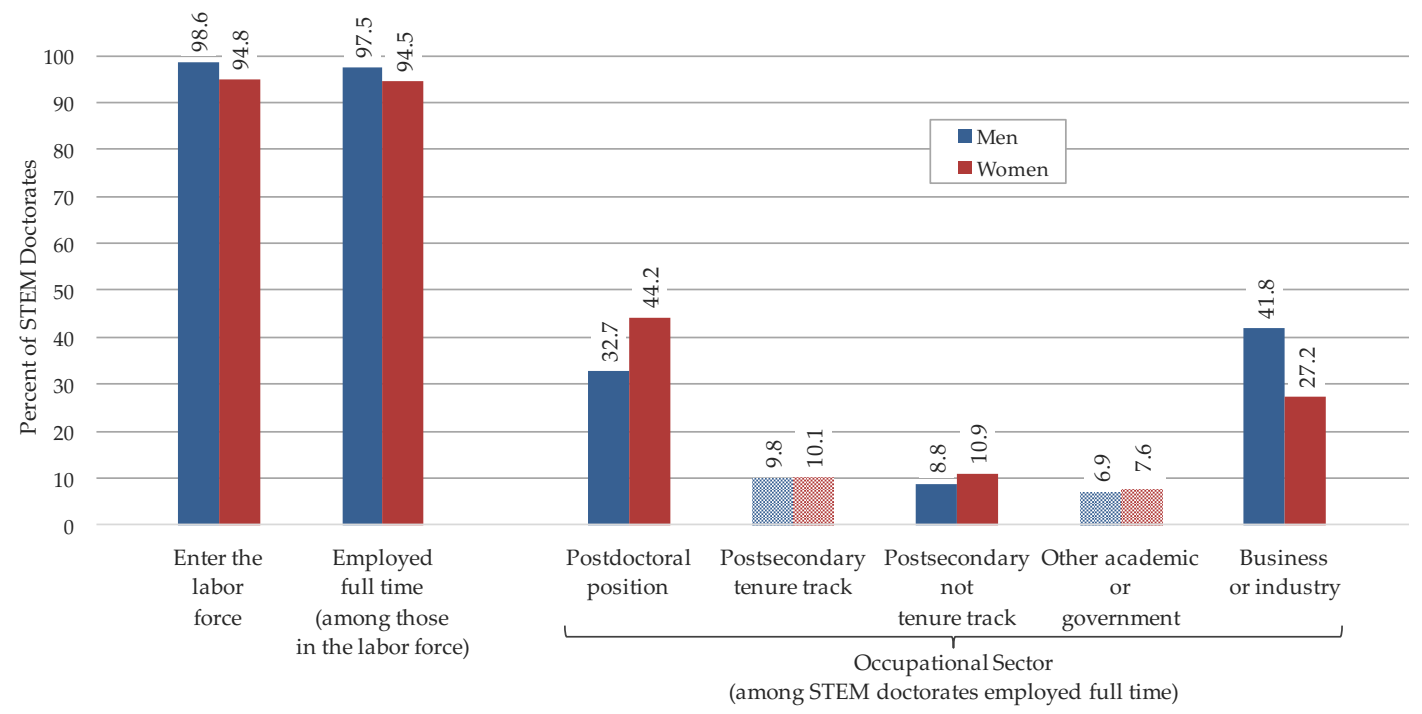

Figure 2. Probability of employment states by gender. Source: Author's calculations using data from the Survey of Doctorate Recipients [22] and the O*NET Occupational Information Network Database [23], 1995-2013. Note: Solid bars represent gender differences that are significant at $\alpha=0.05$.

4 The continuous dependent variables that are modeled with linear regressions are logged to correct for the skewness of their distributions. For each employment outcome, I estimate the following general model:

$$
\begin{gathered}
\text { Outcome }_{i}=\beta_{0}+\beta_{1}(\text { FEMALE })_{i}+\beta_{2}(Y E A R)_{i}+\beta_{3}(\text { FIELD })_{i}+\beta_{4}(\text { FAMILY })_{i}+ \\
\beta_{5}(Y E A R \times \text { FEMALE })_{\mathrm{i}}+\beta_{6}(\text { FIELD } \times \text { FEMALE })_{\mathrm{i}}+\beta_{6}(\text { FAMILY } \times \text { FEMALE })_{\mathrm{i}}+ \\
\varphi_{1}(\text { EDUC })_{\mathrm{i}}+\varphi_{2}\left(\text { EDUC }^{*} \text { FEMALE }\right)_{\mathrm{i}}+\varphi_{1}(X)_{\mathrm{i}}+\varphi_{2}\left(X^{*} \text { FEMALE }\right)_{\mathrm{i}}+\varepsilon_{\mathrm{ij}}
\end{gathered}
$$

where FEMALE is an indicator of the doctorates' self-identified gender (FEMALE $=1$ for females), YEAR represents both the linear and quadratic specification for survey year (which also distinguishes each cohort of doctorates), FIELD represents the categorical indicator of the doctorates' STEM degree field, FAMILY represents the variables measuring family structure, EDUC represents the measures of educational background, and $\mathrm{X}$ is a vector of control variables measuring the doctorates' demographic characteristics and other covariates specifically relevant to each outcome. The models of salary and occupational characteristics (demand for doctoral degree, occupation-degree field relatedness, demand for research skills, and percent female in the occupation) include controls for hours worked, employment sector, and all the other occupational characteristics. Percent female in the occupation is not included as a control variable in the occupational characteristic models because it is very highly correlated with both the other outcome variables and the covariates. Including percent female obscures the estimated association between doctorate gender and the other occupational characteristics that are correlated with percent female. The regression model of occupational percent female, however, includes all occupational characteristic variables as covariates. 
The probability of labor force participation is very high for all doctorates, but women are less likely than men to enter the labor force. Full-time employment is the norm among the STEM doctorates who enter the labor force, but women are slightly less likely than men to work full time hours. Entering a postdoctoral position or a job in business or industry are the most likely post-degree transitions for the doctorates who work full-time but there are significant gender differences in these paths. Women are significantly more likely to enter postdoctoral positions: 44.2 percent of women but only 32.7 percent of men are in postdoctoral positions 2 years after attaining their degree. In contrast, entering business or industry is much more common for men than it is for women. About 42 percent all male doctorates who enter full-time employment within two years of obtaining their doctorate do so in business or industry, compared to only 27.2 percent of women. Entering faculty positions is much less common for STEM doctorates. Ten percent of both women and men enter tenure-track faculty positions in postsecondary institutions. Another 10 percent enter non-tenure-track faculty positions and women are slightly overrepresented among the doctorates in such positions. Entry into "other academic or government" jobs is a path taken by only 7 percent of STEM doctorates and is equally likely for men and women.

Figure 3 presents descriptive statistics for the occupational characteristics relevant to each employment sector the STEM doctorates may enter. Among the doctorates who enter either a postdoctoral or a tenure-track faculty position (panel a of Figure 3), women are less likely than men to attain such positions at research-intensive universities. Panel (b) of Figure 3 shows that there also are gender differences on all four measures of the characteristics of occupations outside of the normative Ph.D.-to-faculty career path. Among the doctorates who enter non-tenure-track postsecondary positions, other academic or government jobs, or business and industry, women are more likely than men to enter occupations that require doctoral-level education and that are closely related to their degree fields. However, the occupations women enter are less likely to primarily focus on research than those occupations entered by men. The significant gender gap in the mean percent female in the occupations entered by men (23.6) and women (33.0) testifies to the prevalence of occupational sex segregation among the STEM doctorates who leave the tenure-track career trajectory: women tend to enter occupations with a greater representation of women than do the male members of their doctoral cohorts. Finally, there is a significant gender gap in earnings among all STEM doctorates who are employed full time. Within two years of earning their degree, women with a STEM doctorate who are employed full time earn, on average, $\$ 12,400$ less per year than their male colleagues.
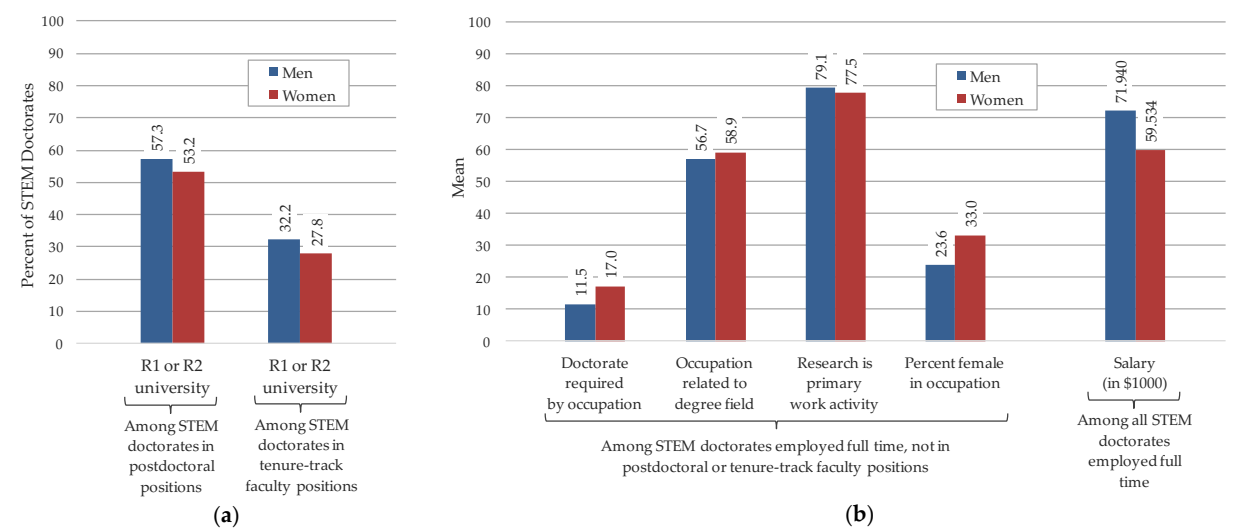

Figure 3. Gender-specific means for the variables measuring the characteristics of occupations entered by STEM doctorates who are employed full time: (a) the percent of STEM doctorates who attain postdoctoral or tenure-track faculty positions at R1 or R2 universities; and (b) salary, and the degree to which an occupation requires doctorate-level education, is closely related the doctorate's degree field, demands research skills, and is female-dominated. Source: Author's calculations using data from the Survey of Doctorate Recipients [22] and the O*NET Occupational Information Network Database [23], 1995-2013. Note: All gender differences are significant at $\alpha=0.05$. 


\subsection{Have the Gender Differences in Early Labor Market Outcomes among STEM Doctorates Changed over Time?}

Results from the multivariate model of each labor market outcome are presented in Figures 4-6. These figures summarize the statistical results relevant to the research questions that motivate this analysis: Have the observed gender differences in the early labor market outcomes of STEM doctorates changed over time?

The results are presented using the estimated marginal effect of FEMALE from the multivariate models for each labor market outcome. The full set of coefficients for each multivariate model are presented in Tables A2-A5. Marginal effects are useful for interpreting the results of both linear and nonlinear models, but they are particularly helpful for the interpretation of estimates from models that include many interaction terms such as those used in this analysis [27]. The figures present the average marginal effect of FEMALE, i.e., the gender gap for the "average" STEM doctorate (when all covariates are set to their mean value), and the $95 \%$ confidence interval for the marginal effect, by year. Negative values of the marginal effect indicate a female deficit in the likelihood of an outcome. If the gender gap in an employment outcome has changed significantly over time the heights of the bars will differ such that the confidence intervals do not overlap.

Figure 4 presents the trends in the estimated gender gap in the rates of labor force participation among all STEM doctorates, and of full-time employment among the doctorates who enter the labor force. These results show that, controlling for the doctorates' educational background and family structure, women are about 3 percent less likely than men to enter the labor force, and the magnitude of the gender gap is unchanged across all 9 cohorts included in this analysis. Among the doctorates who do enter the labor force, women are about 2 percent less likely than men to work full-time, although this small gender gap may have closed as it is not significant for the most recent cohort.

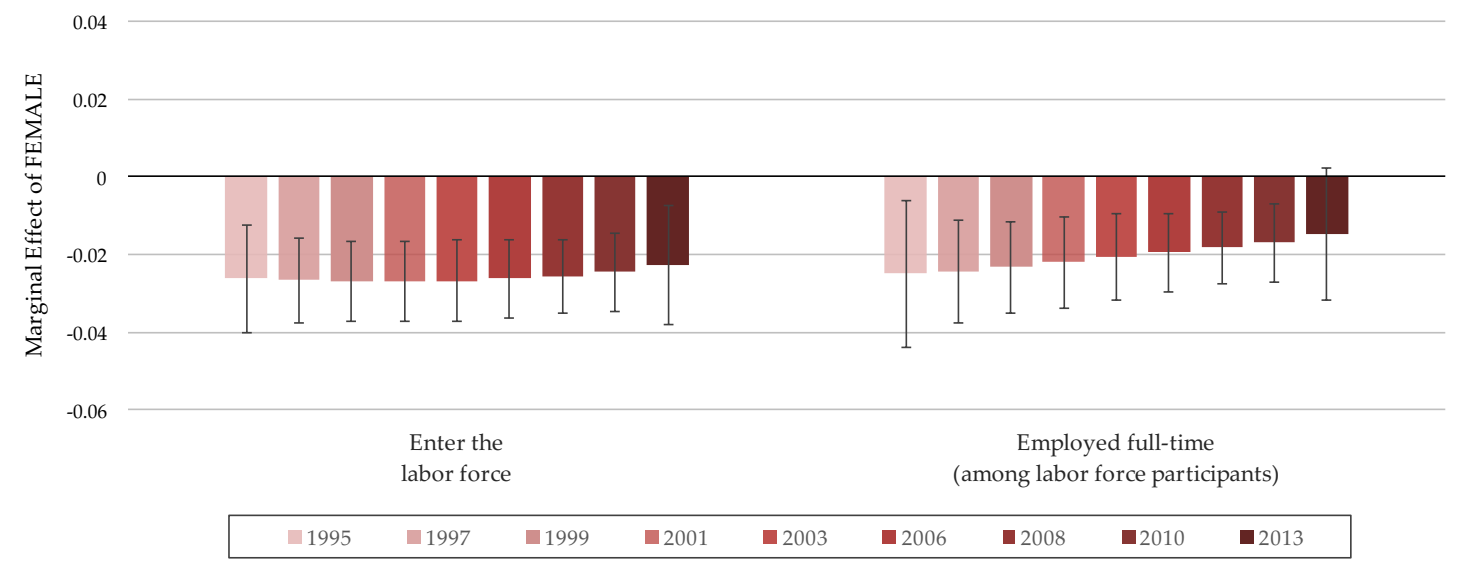

Figure 4. Estimated marginal effects of FEMALE on the likelihood of labor force participation and full-time employment (among those in the labor force), for all STEM doctorates by year. Source: Author's calculations using data from the Survey of Doctorate Recipients [22] and the O*NET Occupational Information Network Database [23], 1995-2013.

Figure 5 presents the cohort-specific gender gaps in the likelihood of each employment sector outcome among full-time employed doctorates. These results identify the significant gender differences in the post-degree career paths of STEM doctorates and how these disparities have changed over time. Among the cohorts of doctorates who earned their degrees in the late 1990s, women were significantly more likely than men to enter postdoctoral positions and less likely to take jobs in business or industry. However, the gender gap in postdoc entry declined and then reversed, and the gap in entering business or industry declined to insignificance-among the 2010 and 2013 cohorts, women are significantly less likely than men to enter postdocs, and there is no gender gap in the likelihood that a STEM doctorate will take a job in business or industry. In contrast, the estimates indicate that there is a growing female 
advantage in the likelihood that a doctorate attains a tenure-track faculty position. Starting with the cohorts who earned their degrees in the early 2000s, the probability that a STEM doctorate enters a tenure-track faculty position has been 2 to 4 percent greater for women than men. In addition, contrary to the expectation that women have been marginalized in non-tenure-track positions more often than men, the results indicate that a female advantage in the likelihood of entering a non-tenure-track faculty position emerged only for the most recent cohorts, while there was gender parity in this employment outcome for the 1995-2008 cohorts.

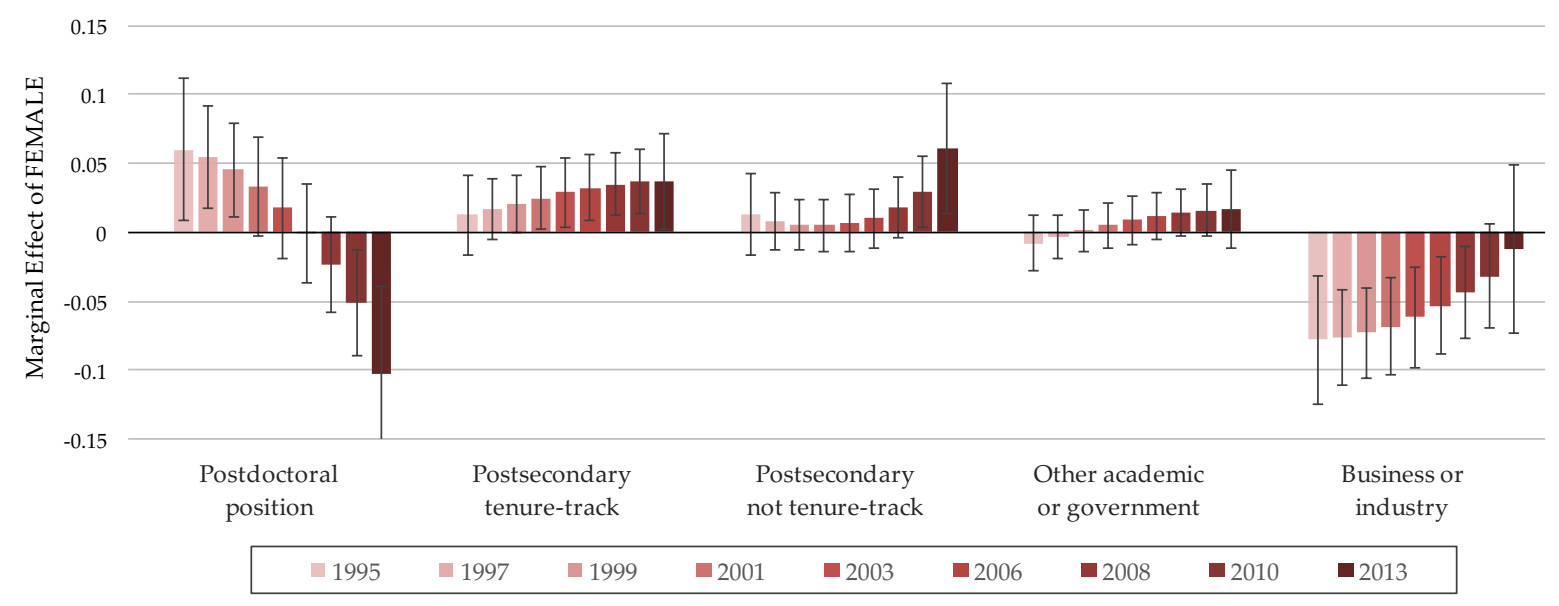

Figure 5. Estimated year-specific marginal effects of FEMALE on employment sector outcome among all STEM doctorates employed full time. Source: Author's calculations using data from the Survey of Doctorate Recipients [22] and the O*NET Occupational Information Network Database [23], 1995-2013.

Figure 6 presents the estimated gender gaps in the characteristics of the occupations entered by STEM doctorates, controlling for the doctorates' educational and family characteristics. The results presented in panel (a) show that among the doctorates who entered postdoctoral or tenure-track faculty positions directly after completing their degree, women and men in all cohorts are equally likely to attain such positions at R1 or R2 universities. There are, however, gender gaps in the characteristics of the jobs attained by doctorates who gain employment in the non-tenure-track postsecondary, other academic or government, or business and industry sectors (panel b). Women are more likely than men to enter jobs that require doctoral-level education, although this gender gap was largest among the 1990s cohorts and has declined across the cohorts. Women and men from all cohorts have been equally likely to utilize their educational investments by entering jobs that are closely related to their degree fields, but women in the 1999-2008 cohorts were less likely to attain research-focused jobs. The significantly positive marginal effects of FEMALE for the percent female in an occupation reflect a significant level of occupational segregation among the STEM doctorates when they first enter the labor market: they show that women are more likely than men to enter jobs with a higher relative representation of women, while men are more likely to enter jobs where men predominate. This tendency toward occupational sex segregation appears to have declined across the cohorts, but remains statistically significant. In addition, the results in panel (c) show that a significant gender gap in earnings emerges at the very start of the STEM doctorates' employment and that this gender gap has changed little across the cohorts. The model estimates indicate that women STEM doctorates start their careers earning 4 to 7 percent less than men with the same employment sector, job characteristics, educational credentials and family characteristics. 


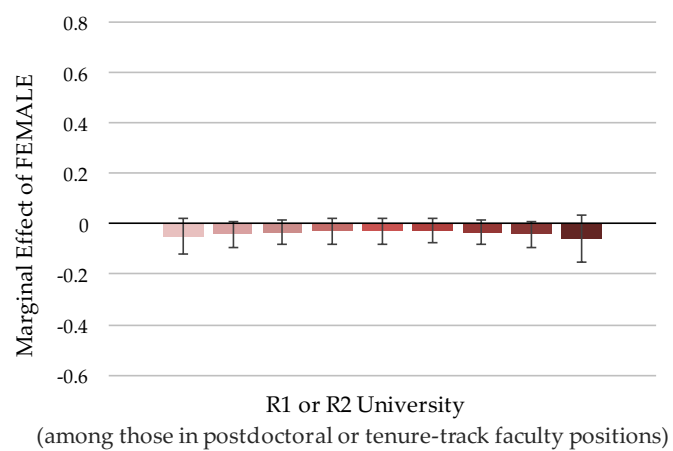

(a)

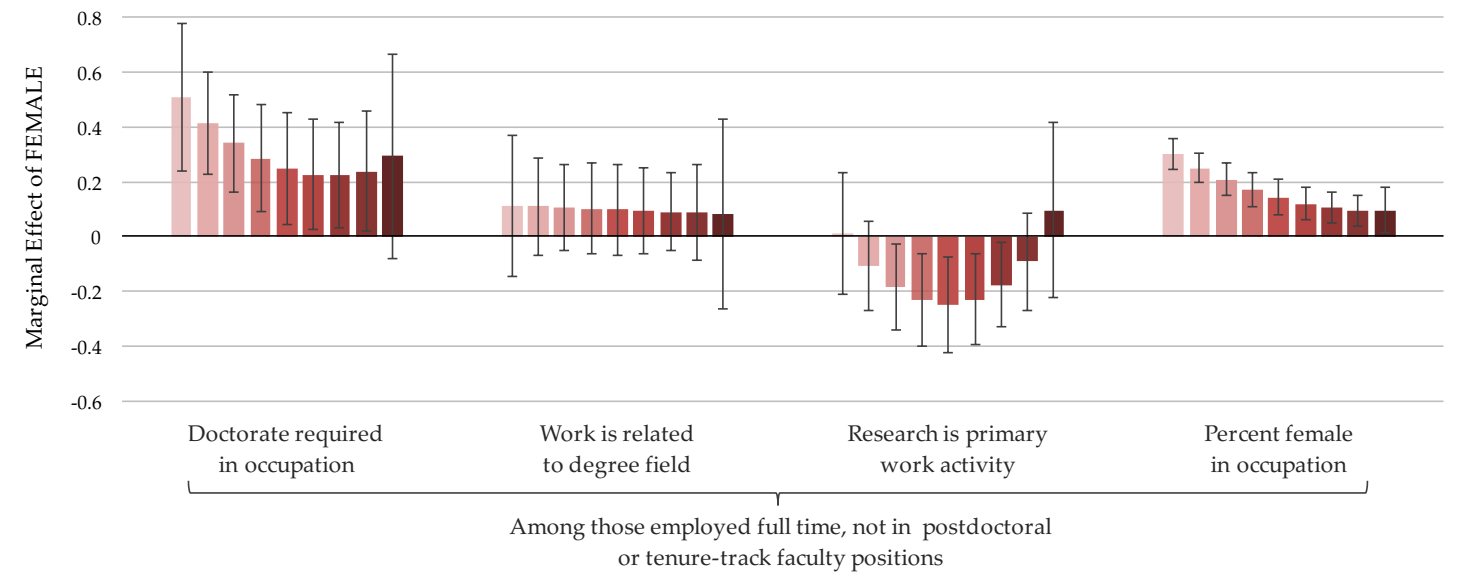

(b)

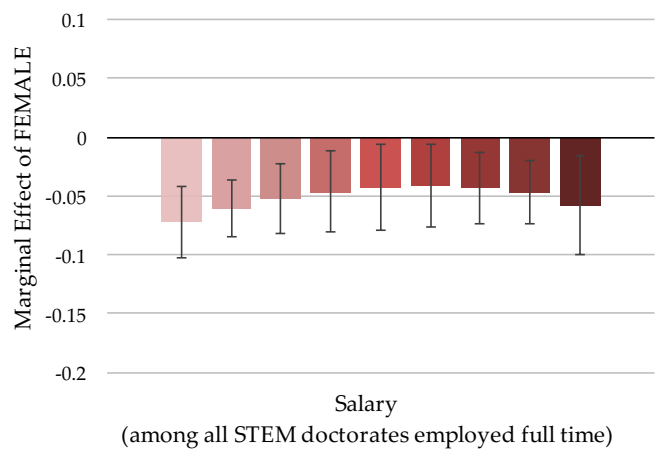

(c)

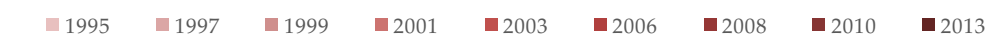

Figure 6. Average estimated marginal effects of FEMALE on the likelihood of: (a) employment at a R1 or R2 university (among STEM doctorates entering postdoctoral or tenure-track faculty positions); (b) employment in an occupation that requires a doctoral degree, that is related to a doctorate's degree field, in which research is the primary work activity, and that is female-dominated (among STEM doctorates employed in non-tenure-track positions, other academic and government positions, or in business or industry); and (c) salary among all STEM doctorates employed full-time. Source: Author's calculations using data from the Survey of Doctorate Recipients [22] and the O*NET Occupational Information Network Database [23], 1995-2013.

\subsection{Do the Gender Differences in Labor Market Outcomes Vary by STEM Field or Family Characteristics?}

The aggregate gender differences in the labor market outcomes of STEM doctorates described above may mask differences across STEM fields or by the family characteristics of the scientists. The patterns may vary across field because of differences in normative career paths and employment 
opportunities, or because of field-specific differences in the representation of women and the experience of bias or discrimination. Similarly, the aggregate gender gaps may not reflect the experience of all scientists but may instead be driven by a distinct subgroup such as those who have young children or are in dual-earner couples. The multivariate analyses test if the aggregate patterns are representative or if specific populations drive them. The results may inform our understanding of the causes of the observed gender disparities and guide interventions aimed at reducing them.

To test if the gender differences in labor market outcomes vary by STEM field or family characteristics, I estimate the marginal effect of FEMALE, i.e., the estimated gender gap, for each of the labor market outcomes separately by degree field, parental status and marital status (controlling for all other covariates). Tables 2 and 3 present the results. In addition, I estimate the marginal effects of FEMALE for job characteristics and salary separately by employment sector to provide additional information about the labor force contexts where gender disparities are most significant. Negative values that are statistically significant indicate a female deficit in the likelihood of an outcome. All estimates control for the doctorates' individual demographics, educational credentials, family characteristics, and employment characteristics (see Tables A2-A5 for the full model specifications). In Tables 2 and 3, the statistical significance of within-group gender differences, e.g., the gender gap among engineering doctorates, is indicated by stars, and significant between-group differences $(\alpha=0.05)$ in the magnitude of the gender gaps, i.e., between the four degree fields or family types, are indicated by bolded text. The focus of this part of the analysis is on the significance of between-group differences (bold values) since these indicate that a covariate is associated with gender disparities in an employment outcome and may therefore help to explain the overall gender gaps in the career trajectories of STEM doctorates.

Table 2. Estimated marginal effect of FEMALE on labor force entry, full-time employment, and employment sector, by degree field and family characteristics

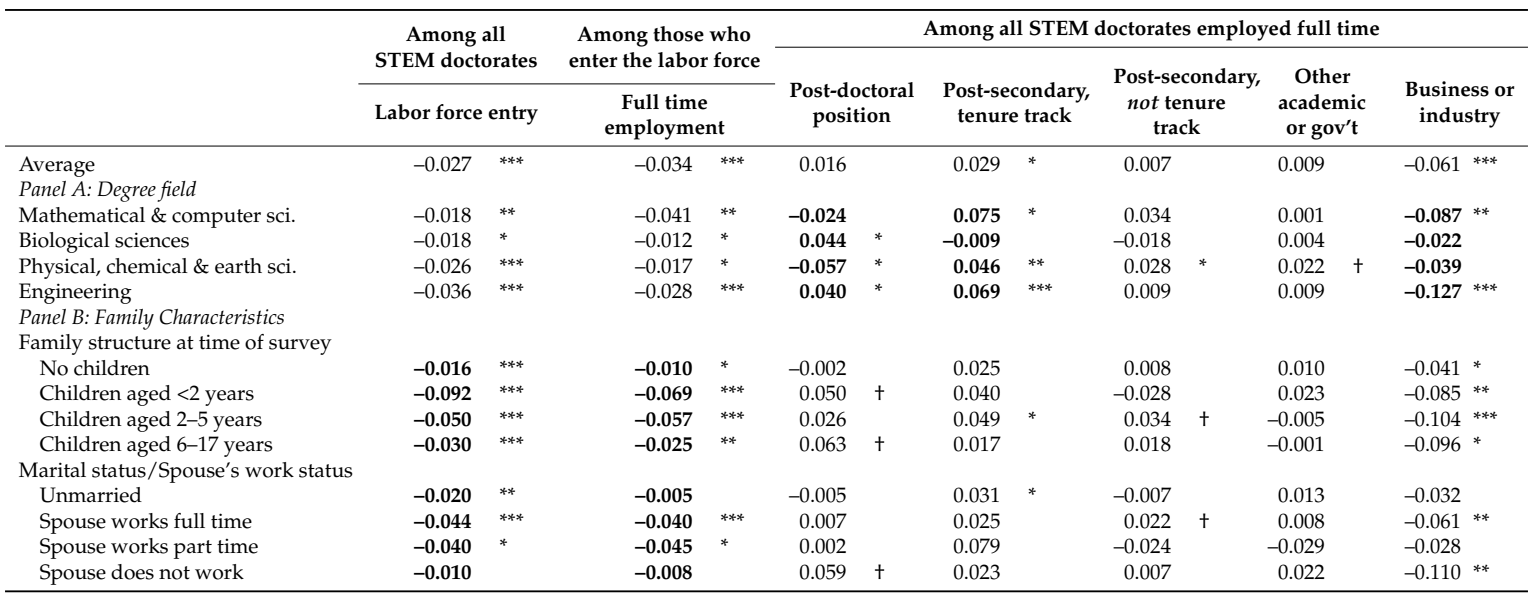

Note: Marginal effects are estimated based on the full regression models of employment outcomes; see Tables A2 and A3 for model specifications and estimated coefficients. Statistical significance of individual marginal effects of FEMALE is indicated by stars: $+p \leq 0.10,{ }^{*} p \leq 0.05,{ }^{* *} p \leq 0.01,{ }^{* * *} p \leq 0.001$. Statistically significant $(\alpha=0.05)$ between-group differences, e.g., between the categories of degree field, in the estimated marginal effect of FEMALE are indicated by bold text. Source: Author's calculations using data from the Survey of Doctorate Recipients [22] and the $O^{*}$ NET Occupational Information Network Database [23], 1995-2013.

\subsubsection{STEM Degree Field}

The marginal effects of FEMALE by degree field for each employment outcome are presented in Panel A of Tables 2 and 3. These results show that gender disparities in labor force participation and attachment, in most job characteristics and in salary do not vary by STEM field, but that gender differences in employment sector do vary by field. A greater proportion of women than men enter postdoctoral positions among doctorates in the biological sciences and engineering, but the gender gap is reversed among doctorates in the physical sciences, where men are more likely than women to 
enter postdocs. The female advantage in attaining tenure-track faculty positions is observed among doctorates in the mathematical and computer sciences, physical sciences, and engineering, but not among biological science doctorates. In addition, the female deficit in the likelihood of taking a job in business or industry is large and significant only among doctorates in engineering and the mathematical and computer sciences. In short, the aggregate pattern of gender differences in the employment sector outcomes (shown in Figure 2 above) appears to be driven by the gender differences among doctorates in engineering and the mathematical and computer sciences. In these fields, which are the most male-dominated of the STEM fields, women are overrepresented among the doctorates who pursue the traditional academic career path by entering a postdoctoral or faculty position, and men are overrepresented among those who enter business or industry. In contrast, there are few gender disparities in the employment outcomes of doctorates in the biological sciences, the most gender balanced field.

Table 3. Estimated marginal effect of FEMALE on job characteristics and salary, by degree field and family characteristics.

\begin{tabular}{|c|c|c|c|c|c|c|c|c|c|c|c|c|}
\hline \multirow[b]{3}{*}{ Average } & \multirow{2}{*}{\multicolumn{2}{|c|}{$\begin{array}{l}\text { Among postdocs \& } \\
\text { tenure-track faculty }\end{array}$}} & \multicolumn{8}{|c|}{$\begin{array}{l}\text { Among STEM doctorates employed full time, not in } \\
\text { postdoctoral or tenure-track positions }\end{array}$} & \multirow{2}{*}{\multicolumn{2}{|c|}{$\begin{array}{c}\begin{array}{c}\text { Among all STEM } \\
\text { doctorates employed } \\
\text { full time }\end{array} \\
\text { Salary } \\
\end{array}$}} \\
\hline & & & \multicolumn{2}{|c|}{$\begin{array}{l}\text { Doctorate } \\
\text { required in } \\
\text { occupation }\end{array}$} & \multicolumn{2}{|c|}{$\begin{array}{l}\text { Work is } \\
\text { related to } \\
\text { degree field }\end{array}$} & \multicolumn{2}{|c|}{$\begin{array}{l}\text { Research is } \\
\text { primary work } \\
\text { activity }\end{array}$} & \multicolumn{2}{|c|}{$\begin{array}{c}\text { Percent } \\
\text { female in } \\
\text { occupation }\end{array}$} & & \\
\hline & -0.058 & $* * *$ & 0.244 & * & 0.097 & & -0.247 & $* *$ & 0.137 & $* * *$ & -0.046 & $*$ \\
\hline Mathematical \& computer sci. & -0.028 & & 0.200 & & 0.182 & & -0.495 & $* *$ & 0.115 & * & -0.028 & \\
\hline Engineering & -0.068 & & 0.539 & $* * *$ & -0.019 & & -0.302 & * & 0.165 & $* *$ & -0.032 & \\
\hline \multicolumn{13}{|l|}{ Panel B: Family Characteristics } \\
\hline \multicolumn{13}{|l|}{ Family structure at time of survey } \\
\hline No children & -0.039 & & 0.274 & * & 0.094 & & -0.243 & ** & 0.143 & $* * *$ & -0.053 & $* *$ \\
\hline Children aged $<2$ years & -0.017 & & 0.157 & & 0.308 & t & -0.181 & & 0.070 & & -0.023 & \\
\hline Children aged $2-5$ years & -0.038 & & 0.214 & & -0.121 & & -0.135 & & 0.152 & $* * *$ & -0.027 & \\
\hline Children aged $6-17$ years & 0.032 & & 0.222 & & 0.107 & & -0.512 & $* *$ & 0.174 & $* *$ & -0.056 & + \\
\hline Spouse does not work & -0.074 & & 0.101 & & 0.088 & & -0.455 & $* *$ & 0.114 & & -0.086 & $* *$ \\
\hline \multicolumn{13}{|l|}{ Panel C: Employment sector } \\
\hline Postdoctoral position & -0.021 & & & & & & & & & & -0.012 & \\
\hline Postsecondary, tenure track & -0.040 & & & & & & & & & & -0.057 & * \\
\hline Postsecondary, not tenure track & & & -0.177 & & 0.072 & & -0.228 & & 0.134 & $* *$ & -0.033 & \\
\hline Other academic or government & & & -0.003 & & 0.194 & & -0.195 & & 0.198 & $* * *$ & -0.088 & $* *$ \\
\hline Business or industry & & & 0.396 & $* * *$ & 0.085 & & -0.262 & $* *$ & 0.126 & $* *$ & -0.057 & * \\
\hline
\end{tabular}

Note: Marginal effects are estimated based on the full regression models of employment outcomes; see Tables A4 and A5 for model specifications and estimated coefficients. Statistical significance of individual marginal effects of FEMALE is indicated by stars: $+p \leq 0.10,{ }^{*} p \leq 0.05,{ }^{* *} p \leq 0.01,{ }^{* * *} p \leq 0.001$. Statistically significant $(\alpha=0.05)$ between-group differences, e.g., between the categories of degree field, in the estimated marginal effect of FEMALE are indicated by bold text. Source: Author's calculations using data from the Survey of Doctorate Recipients [22] and the $O^{*} N E T$ Occupational Information Network Database [23], 1995-2013.

The estimates presented in Panel A of Table 3 show that the gender differences in the types of jobs the doctorates attain generally do not vary significantly across degree field. Among the doctorates that enter postdoctoral positions or tenure-track faculty jobs, women and men from all degree fields are equally likely to attain these positions at research-intensive universities. For the doctorates that do not enter postdocs or tenure-track faculty positions, there are gender differences in the types of jobs they attain but, with only one exception, the between-field disparities do not attain statistical significance. The aggregate female advantage in the likelihood that a doctorate attains a job that requires Ph.D.-level education is driven by those in engineering fields. Women and men are, on average, equally likely to attain jobs that are related to their degree field, although women with physical science doctorates are more likely than men to utilize their field-specific education on the job. In contrast, the female deficits in the attainment of research-oriented jobs and the tendency toward occupation sorting by sex are significant for doctorates in all degree fields, except the biological sciences. Yet, the biological sciences 
and the physical sciences are the two fields in which women doctorates earn significantly less than men even when they have equivalent background and employment characteristics.

The estimated marginal effects of FEMALE presented in Panel $C$ of Table 3 provide additional information about the labor market contexts in which these occupational gender disparities occur. Both the female advantage in attainment of jobs that require a doctoral degree and the female disadvantage in the attainment of research jobs are concentrated among those who enter business or industry jobs. The tendency for doctorates to segregate into gender-typed occupations, however, is universal across the non-tenure-track postsecondary, other academic and government, and business and industry sectors. The gender gap in salary is also universal across sectors, although it reaches statistical significance only among doctorates who enter tenure-track faculty positions, other academic or government jobs, and positions in business or industry.

\subsubsection{Family Structure}

The estimated gender disparities in labor force entry, full-time work and employment sector by the measures of family structure are presented in Panel B of Tables 2 and 3. These estimates show that gender differences in labor force participation and the likelihood of working full time are strongly associated with the STEM doctorates' family characteristics but that subsequent employment outcomes are not. The female deficit in labor force participation is significant for all family structures but it is greatest among doctorates with young children (aged less than 2 years) and those in dual-earner marriages (doctorates' whose spouses work either full or part time), indicating that gender differences in the influence of the household division of labor, especially as it relates to childbearing and caring for young children, is a significant cause of the gender gap in labor force participation among STEM doctorates. The gender gap in the likelihood of full-time employment is also strongly associated with the parenting of young children and dual-career marital status. Among doctorates who have no children, the rate of full-time employment is one percent lower for women than men, but for doctorates with young children, the likelihood of full-time employment is 5-9 percent lower for women than men. Similarly, there is no gender gap in the likelihood of full-time employment among unmarried doctorates and doctorates whose spouses do not work, but the gender gap increases to 4 percent among doctorates who have spouses who work either full or part time.

The estimated gender differences in the doctorates' employment sector outcomes, the characteristics of the jobs they attain and the salaries they earn are presented in Panel B of Table 3. These results show that the aggregate pattern of gender differences in these employment outcomes do not vary by the doctorates' family status, so the gender gaps in these labor force outcomes cannot be explained by gender differences in the distribution or influence of family characteristics. Notably, this analysis provides no evidence that marital or parental status affects the female advantage in the likelihood of employment in tenure-track faculty positions or the female deficit in the likelihood of employment in business or industry. Nor do family characteristics appear to affect gender differences in the types of jobs doctorates attain, their salary, or the tendency for doctorates to enter sex-typed occupations. In fact, after controlling for all covariates, the gender gap in salary is significant only for doctorates who are childless, for whom there can be no effect of parenthood, and those who have spouses who work part-time or not at all, for whom dual-career conflicts should be minimal.

\section{Discussion}

This analysis provides some insight into the gender disparities that characterize the transition of STEM doctorates to the labor market and that may affect their subsequent career trajectories. The time frame of this analysis is narrow-the 2 years following the doctorate's degree attainment-so the parities and disparities identified are not necessarily representative of later career outcomes since they have yet to be affected by any significant exposure to labor market influences. They are consequential, however, since early career transitions and achievements may at least condition, if not determine, subsequent opportunities and outcomes. 
Among the nine cohorts of STEM doctorates who earned their degrees between 1995 and 2013, I find that women are less likely than men to enter the labor force and work full-time, and that these disparities are consistent across STEM fields and have changed only slightly across the cohorts. I also find significant gender differences in the types of employment attained by STEM doctorates and some of these results contradict long-held perceptions of gender disparities in the STEM labor market. The results indicate that among the early cohorts of doctorates, women were more likely than men to enter postdoctoral positions but that the gender gap declined and then reversed so that men are now overrepresented among the doctorates entering postdoctoral positions. The gender gap in entry into postdoctoral positions varies by STEM field so the stark aggregate trend may reflect field-specific changes in the availability and career necessity of postdocs, as much as it may reflect changes in the behavior of men and women: while postdoctoral positions have long been a normative part of the career trajectory in the female-dominated biological sciences, over time they are increasingly available and a required precursor to faculty positions in the male dominate STEM fields.

In contrast to prior studies, I find that women are more likely than men to enter tenure-track faculty positions within two years of completing their doctorate and that they are as likely as men to obtain these positions at research-intensive universities. I also find that the overrepresentation of women among doctorates who attain non-tenure-track academic positions emerged only among the most recent cohorts, when the availability of such positions increased significantly. The discrepancy between the results reported here and the existing literature may be attributed to differences in research design, and they thereby highlight the need for carefully constructed analyses. This study explicitly parses gender disparities in labor force participation and attachment from employment outcomes whereas prior analyses often conflate these, and thereby overestimate the gender gap in attainment of faculty positions, by simply comparing the representation of women among tenure-track assistant professors to that among recent cohorts of doctorates without additional controls. Furthermore, by focusing on a narrow post-degree period, the results of this analysis likely understate the gender differences that ultimately develop among each cohort of doctorates, but they more accurately indicate that those disparities develop at later points in the career trajectory. These points underscore the necessity of disaggregating employment transitions to the most detailed level possible to accurately identify the processes that drive gender differences in career trajectories. By looking at narrow slices of the career trajectories and explicitly examining how they are connected, we can more accurately identify where the disparities are occurring, what are their causes, and we therefore will be better able to develop policies that will generate greater gender equity in STEM career development.

By using an inclusive conceptualization of employment outcomes that includes and attempts to disaggregate non-academic career tracks, this analysis provides a more comprehensive and nuanced picture of gender differences in the career paths of STEM doctorates and in the likelihood they will "leave" science. The results show that women are less likely than men to gain employment in business and industry and that this gender disparity is greatest among doctorates in engineering and the mathematical and computer sciences, but that it may have declined over time. Among the doctorates who enter business or industry, the alternative approach to identifying who "stays in the pipeline" developed for this analysis shows that women are more likely than men to enter jobs that require a doctorate, and they are at least as likely as men to enter occupations that are related to their degree field. However, I also find that women in all fields, except the biological sciences, are significantly less likely than men to enter research-oriented jobs. Therefore, women may persist in STEM but are "lost" from research jobs. The gender-specific patterns of education-occupation matching identified in this analysis reflect processes of gender sorting across a range of occupational characteristics that has been under-appreciated and warrant further investigation. A more well-known pattern that this analysis clearly identifies as a persistent influence on the occupational attainment of doctorates, is occupational segregation by sex. In addition, while the results of this analysis suggest that the extent to which STEM doctorates enter gender-segregated occupations has declined over time, it remains significant among the most recent cohorts and in all STEM fields except the biological sciences. 
The results of this analysis echo the refrain of the growing body of the gender and work literature: family structure has a negative impact on the employment outcomes of women in the STEM fields. However, this study joins the chorus in a limited way: I find that the presence of children and the gendered impact of being in a dual-earner couple are strong negative influences on the early employment outcomes of women, but only because they disproportionately inhibit their labor market entry and full-time labor force attachment. Gender differences in other dimensions of the transition into the labor market are not influenced as strongly by marital or parental status, nor is there evidence that the female-specific influence of the presence of young children or a working spouse are driving either the differential sorting of men and women across employment sectors and occupations, or the significant gender gap in earnings.

Overall, these results indicate that there has been some progress toward gender equity at the earliest stages of the career trajectories of STEM doctorates but that this progress is slow and variable across STEM fields. In general, the greatest gender gaps remain in those fields where women's representation continues to lag, but disparities in outcomes persist even when gender parity in representation is approached. Further analysis of the labor market processes and outcomes that follow the initial transitions investigated here should assess if similar progress toward equity is being attained and how the gender disparities vary by race/ethnicity and other social identities. The experiences of STEM doctorates who enter jobs in business and industry is an area that is particularly in need of both data collection and analysis. Although an increasing number of STEM doctorates enter business and industry, there are few data sources that can adequately inform our understanding of their labor market experiences and outcomes, or the forces that influence the significant gender disparities in that sector which this analysis identified.

Supplementary Materials: The following are available online at www.mdpi.com/2076-0760/6/1/24/s1, Table S1: Percent distribution by occupational category, for analytical and operational samples, separately by gender and degree field.

Acknowledgments: This study builds on work supported by a postdoctoral fellowship from the National Academy of Education and Spencer Foundation. I thank Maria Stanfors, the participants at the 2010 Lund University "Gender in Academia" conference, the editors and anonymous reviewers for helpful comments and suggestions on earlier drafts of this paper.

Conflicts of Interest: The author declares no conflict of interest.

\section{Appendix A}

Table A1. Percent distribution of analytical and operational samples by degree field and gender.

\begin{tabular}{|c|c|c|c|c|c|c|c|c|c|c|}
\hline & \multicolumn{5}{|c|}{ Sample of Recent Doctorates } & \multicolumn{5}{|c|}{ Operational Sample of Doctorates } \\
\hline & Total & Males & \multicolumn{2}{|c|}{ Females } & \%Female & Total & Males & \multicolumn{2}{|c|}{ Females } & \%Female \\
\hline Sample size $(n)$ & 18,687 & 12,953 & \multicolumn{2}{|c|}{5734} & 30.68 & 63,962 & 47,700 & \multirow{2}{*}{\multicolumn{2}{|c|}{16,262}} & 25.42 \\
\hline Degree field & & & & & & & & & & \\
\hline \multicolumn{11}{|l|}{ Math \& computer sciences } \\
\hline Computer \& information sciences & 5.25 & 6.09 & 3.37 & $* * *$ & 19.68 & 4.61 & 5.12 & 3.11 & $* * *$ & 17.15 \\
\hline Mathematics \& statistics & 6.00 & 6.22 & 5.50 & + & 28.13 & 5.57 & 5.80 & 4.91 & $* * *$ & 22.40 \\
\hline Agricultural \& food sciences & 2.95 & 2.79 & 3.31 & $t$ & 34.45 & 3.58 & 3.56 & 3.62 & & 25.76 \\
\hline \multicolumn{11}{|l|}{ Biological sciences } \\
\hline Biochemistry \& biophysics & 5.24 & 4.65 & 6.59 & $* * *$ & 38.57 & 1.54 & 1.33 & 2.16 & $* * *$ & 35.70 \\
\hline Cell \& molecular biology & 5.89 & 4.33 & 9.41 & $* * *$ & 49.06 & 1.75 & 1.52 & 2.43 & $* * *$ & 35.33 \\
\hline Microbiology & 2.60 & 1.86 & 4.27 & $* * *$ & 50.40 & 0.72 & 0.35 & 1.81 & $* * *$ & 63.87 \\
\hline Other biological sciences & 20.14 & 15.42 & 30.79 & $* * *$ & 46.91 & 29.86 & 23.87 & 47.44 & $* * *$ & 40.40 \\
\hline \multicolumn{11}{|l|}{ Physical sciences } \\
\hline Chemistry, except biochemistry & 11.11 & 10.77 & 11.87 & * & 32.80 & 12.17 & 12.04 & 12.53 & & 26.19 \\
\hline Earth, atmospheric \& ocean sciences & 3.34 & 3.34 & 3.34 & & 30.68 & 3.32 & 3.41 & 3.08 & * & 23.59 \\
\hline Physics, astronomy \& astrophysics & 7.88 & 9.56 & 4.09 & $* * *$ & 15.94 & 8.38 & 9.67 & 4.58 & $* * *$ & 13.90 \\
\hline \multicolumn{11}{|l|}{ Engineering } \\
\hline Chemical engineering & 3.39 & 3.79 & 2.47 & $* * *$ & 22.34 & 3.39 & 3.80 & 2.18 & $* * *$ & 16.38 \\
\hline Civil engineering & 2.55 & 3.00 & 1.55 & $* * *$ & 18.63 & 2.38 & 2.82 & 1.08 & $* * *$ & 11.58 \\
\hline Electrical \& computer engineering & 8.80 & 10.85 & 4.17 & $* * *$ & 14.54 & 8.49 & 10.25 & 3.33 & $* * *$ & 9.95 \\
\hline Materials, metallurgical \& mechanical & 7.41 & 9.06 & 3.69 & $* * *$ & 15.28 & 5.18 & 6.25 & 2.01 & $* * *$ & 9.89 \\
\hline Other engineering & 7.45 & 8.28 & 5.58 & $* * *$ & 22.97 & 9.07 & 10.22 & 5.71 & $* * *$ & 16.01 \\
\hline
\end{tabular}

Note: $+p \leq 0.10,{ }^{*} p \leq 0.05,{ }^{* *} p \leq 0.01,{ }^{* * *} p \leq 0.001$, for two-tailed test of sex differences. Source: Author's calculations using data from the Survey of Doctorate Recipients [22], 1995-2013. 
Table A2. Estimated coefficients from logit models of labor force entry and employment vs. post-doctoral position.

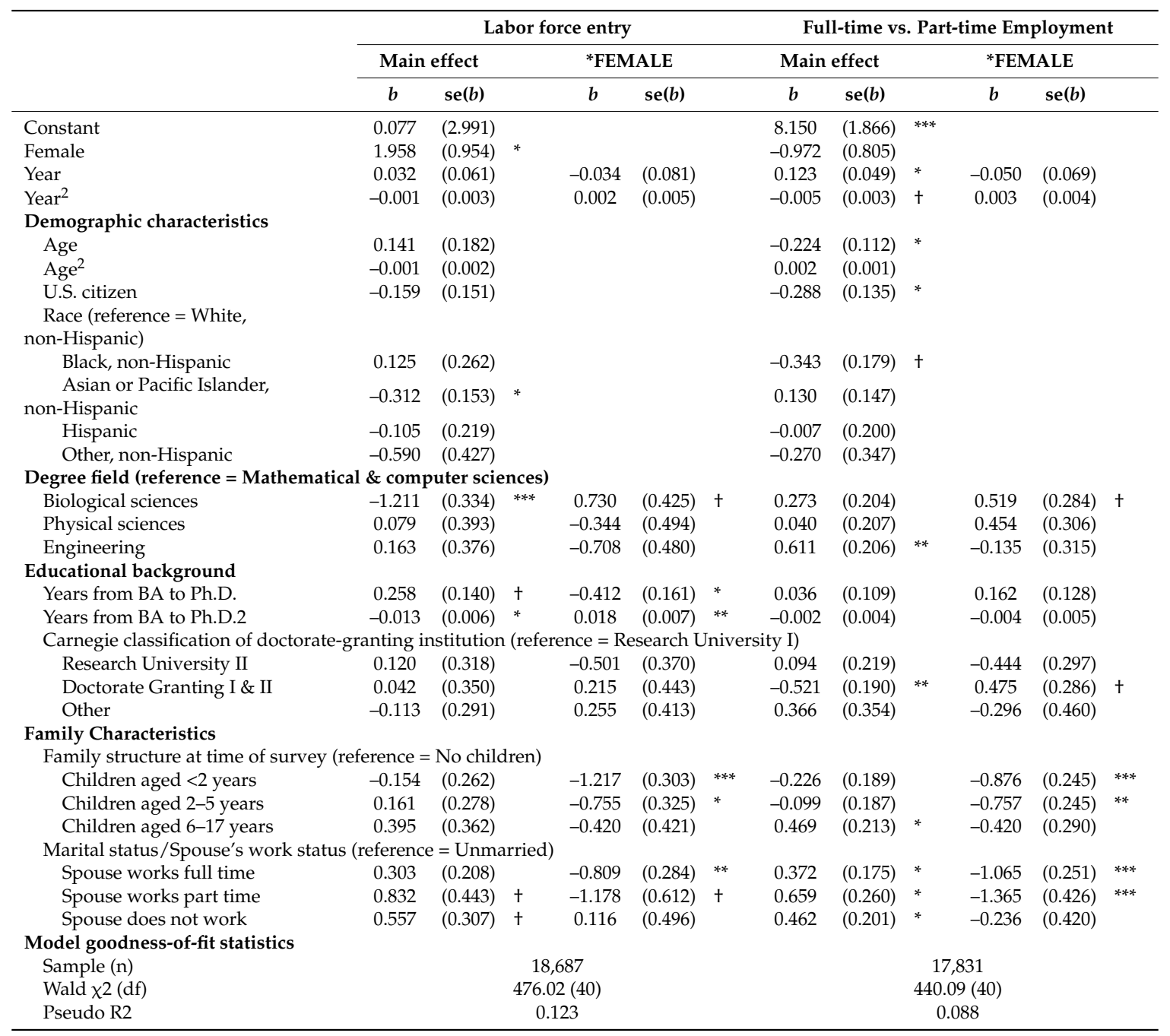

Note: $\dagger p \leq 0.10,{ }^{*} p \leq 0.05,{ }^{* *} p \leq 0.01,{ }^{* * *} p \leq 0.001$, for two-tailed test of sex differences. Source: Author's calculations using data from the Survey of Doctorate Recipients [22] and the O*NET Occupational Information Network Database [23], 1995-2013. 
Table A3. Estimated coefficients from multinomial logit models of employment sector.

\begin{tabular}{|c|c|c|c|c|c|c|c|c|c|c|c|c|c|c|c|c|}
\hline & \multicolumn{16}{|c|}{ Reference Category = Business or Industry } \\
\hline & \multicolumn{4}{|c|}{ Postdoctoral Position } & \multicolumn{4}{|c|}{ Faculty Position, Tenure Track } & \multicolumn{4}{|c|}{ Faculty Position, Not Tenure Track } & \multicolumn{4}{|c|}{ Other Academic or Government } \\
\hline & \multicolumn{2}{|c|}{ Main Effect } & \multicolumn{2}{|c|}{${ }^{*}$ Female } & \multicolumn{2}{|c|}{ Main Effect } & \multicolumn{2}{|c|}{${ }^{*}$ Female } & \multicolumn{2}{|c|}{ Main Effect } & \multicolumn{2}{|c|}{${ }^{*}$ Female } & \multicolumn{2}{|c|}{ Main Effect } & \multicolumn{2}{|c|}{${ }^{*}$ Female } \\
\hline & $b$ & se(b) & $b$ & se(b) & $b$ & se(b) & $b$ & se(b) & $b$ & se(b) & $b$ & se $(b)$ & $b$ & se(b) & $b$ & se $(b)$ \\
\hline Constant & -0.619 & $(0.165)$ & & & -1.826 & $(1.441)$ & & & -3.740 & $(1.521)^{*}$ & & & -8.365 & $(1.666)^{* * *}$ & & \\
\hline Female & 0.740 & $(0.447)+$ & & & -0.028 & $(0.578)$ & & & -0.132 & $(0.605)$ & & & 0.269 & $(0.678)$ & & \\
\hline Year & -0.065 & $(0.021)^{* *}$ & -0.002 & $(0.038)$ & 0.041 & $(0.031)$ & 0.005 & $(0.058)$ & -0.026 & $(0.032)$ & -0.041 & $(0.056)$ & -0.005 & $(0.033)$ & 0.037 & $(0.060)$ \\
\hline Year $^{2}$ & 0.005 & $(0.001)^{* * *}$ & -0.002 & $(0.002)$ & -0.002 & $(0.002)$ & 0.000 & $(0.003)$ & 0.003 & $(0.002)+$ & 0.002 & $(0.003)$ & 0.000 & $(0.002)$ & -0.001 & $(0.003)$ \\
\hline \multicolumn{17}{|l|}{ Demographic characteristics } \\
\hline Age & -0.007 & $(0.071)$ & & & 0.022 & $(0.087)$ & & & 0.083 & $(0.090)$ & & & 0.253 & $(0.098) * *$ & & \\
\hline $\mathrm{Age}^{2}$ & 0.000 & $(0.001)$ & & & 0.000 & $(0.001)$ & & & 0.000 & $(0.001)$ & & & -0.003 & $(0.001)^{*}$ & & \\
\hline U.S. citizen & -0.385 & $(0.062) * * *$ & & & 0.360 & $(0.083) * * *$ & & & 0.216 & $(0.092) *$ & & & 1.024 & $(0.110)^{* * *}$ & & \\
\hline \multicolumn{17}{|c|}{ Race $($ reference $=$ White, non-Hispanic) } \\
\hline Black, non-Hispanic & -0.214 & $(0.120)+$ & & & 0.224 & $(0.136)$ & & & 0.249 & $(0.138)+$ & & & 0.363 & $(0.150) *$ & & \\
\hline Asian or Pacific Islander, non-Hisp. & -0.213 & $(0.063)^{* * *}$ & & & -0.710 & $(0.091) * * *$ & & & -0.426 & $(0.099) * * *$ & & & -0.585 & $(0.113)^{* * *}$ & & \\
\hline Hispanic & 0.061 & $(0.101)$ & & & 0.062 & $(0.127)$ & & & -0.013 & $(0.132)$ & & & 0.079 & $(0.140)$ & & \\
\hline Other, non-Hispanic & 0.081 & $(0.227)$ & & & -0.094 & $(0.343)$ & & & 0.310 & $(0.324)$ & & & 0.554 & $(0.255)$ * & & \\
\hline \multicolumn{17}{|c|}{ Degree field (reference $=$ Mathematical \& computer sciences) } \\
\hline Biological sciences & 2.089 & $(0.107)^{* * *}$ & 0.129 & $(0.196)$ & -0.560 & $(0.119) * * *$ & -0.491 & $(0.205) *$ & 0.310 & $(0.324)$ & -0.132 & $(0.605)$ & 0.554 & $(0.255) *$ & 0.269 & $(0.678)$ \\
\hline Physical sciences & 1.109 & $(0.104) * * *$ & -0.100 & $(0.203)$ & -1.222 & $(0.118)^{* * *}$ & 0.143 & $(0.213)$ & 0.836 & $(0.130)^{* * * *}$ & -0.597 & $(0.221)^{* *}$ & 0.815 & $(0.169)^{* * *}$ & -0.047 & $(0.305)$ \\
\hline Engineering & -0.521 & $(0.105) * * *$ & 0.414 & $(0.212) \dagger$ & -1.450 & $(0.104) * * *$ & 0.306 & $(0.200)$ & -0.186 & $(0.140)$ & -0.093 & $(0.243)$ & 0.326 & $(0.169)+$ & 0.166 & $(0.316)$ \\
\hline \multicolumn{17}{|l|}{ Educational background } \\
\hline Years from BA to Ph.D. & 0.169 & $(0.051) * * *$ & -0.139 & $(0.073)+$ & 0.055 & $(0.068)$ & 0.032 & $(0.095)$ & 0.032 & $(0.070)$ & 0.071 & $(0.097)$ & 0.059 & $(0.077)$ & -0.070 & $(0.109)$ \\
\hline Years from BA to Ph.D. ${ }^{2}$ & -0.008 & $(0.002)^{* * *}$ & -0.099 & $(0.230)$ & -0.003 & $(0.003)$ & -0.781 & $(0.412) \dagger$ & -0.002 & $(0.003)$ & -0.001 & $(0.004)$ & -0.001 & $(0.003)$ & 0.005 & $(0.004)$ \\
\hline Research University II & -0.192 & $(0.091) *$ & 0.133 & $(0.174)$ & 0.085 & $(0.119)$ & 0.105 & $(0.225)$ & -0.277 & $(0.136)^{*}$ & 0.303 & $(0.244)$ & 0.234 & $(0.132)+$ & -0.023 & $(0.240)$ \\
\hline Doctorate Granting I \& II & -0.461 & $(0.100)^{* * *}$ & 0.243 & $(0.175)$ & -0.006 & $(0.126)$ & -0.005 & $(0.221)$ & -0.030 & $(0.135)$ & 0.203 & $(0.228)$ & 0.081 & $(0.140)$ & -0.015 & $(0.258)$ \\
\hline Other & 0.159 & $(0.150)$ & -0.099 & $(0.230)$ & 0.073 & $(0.234)$ & -0.781 & $(0.412)+$ & 0.680 & $(0.179) * * *$ & -0.732 & $(0.308) *$ & 0.591 & $(0.207)^{* *}$ & -0.859 & $(0.374)^{*}$ \\
\hline \multicolumn{17}{|l|}{ Family Characteristics } \\
\hline \multicolumn{17}{|c|}{ Family structure at time of survey (excluded = No children) } \\
\hline Children aged $<2$ years & -0.184 & $(0.076)^{*}$ & 0.212 & $(0.149)$ & 0.165 & $(0.099) \dagger$ & 0.127 & $(0.206)$ & 0.182 & $(0.107)+$ & -0.350 & $(0.218)$ & -0.226 & $(0.122) \dagger$ & 0.326 & $(0.244)$ \\
\hline Children aged $2-5$ years & -0.087 & $(0.078)$ & 0.195 & $(0.164)$ & 0.060 & $(0.104)$ & 0.305 & $(0.211)$ & -0.037 & $(0.111)$ & 0.452 & $(0.217)^{*}$ & 0.150 & $(0.113)$ & -0.078 & $(0.249)$ \\
\hline Children aged $6-17$ years & -0.234 & $(0.099) *$ & 0.277 & $(0.195)$ & 0.186 & $(0.115)$ & -0.042 & $(0.232)$ & -0.107 & $(0.127)$ & 0.233 & $(0.235)$ & 0.071 & $(0.126)$ & -0.057 & $(0.264)$ \\
\hline \multicolumn{17}{|c|}{ Marital status/Spouse's work status (reference $=$ Unmarried) } \\
\hline Spouse works full time & -0.354 & $(0.073) * * *$ & 0.095 & $(0.120)$ & -0.118 & $(0.108)$ & -0.003 & $(0.176)$ & -0.356 & $(0.109)^{* * *}$ & 0.353 & $(0.174) *$ & -0.081 & $(0.122)$ & -0.016 & $(0.189)$ \\
\hline Spouse works part time & -0.331 & $(0.114) * *$ & 0.000 & $(0.271)$ & 0.302 & $(0.146)^{*}$ & 0.161 & $(0.327)$ & -0.073 & $(0.157)$ & -0.209 & $(0.398)$ & 0.275 & $(0.161)+$ & -0.635 & $(0.418)$ \\
\hline Spouse does not work & -0.519 & $(0.085) * * *$ & 0.388 & $(0.196) *$ & 0.016 & $(0.120)$ & 0.079 & $(0.264)$ & -0.436 & $(0.125) * * *$ & 0.335 & $(0.275)$ & -0.064 & $(0.145)$ & 0.270 & $(0.311)$ \\
\hline \multirow{2}{*}{\multicolumn{17}{|c|}{ Model goodness-of-fit statistics }} \\
\hline Sample $(n)$ & & & & & & & & & 153 & & & & & & & \\
\hline Wald $\chi^{2}(\mathrm{df})$ & & & & & & & & 3607. & $3(160)$ & & & & & & & \\
\hline Pseudo $R^{2}$ & & & & & & & & & & & & & & & & \\
\hline
\end{tabular}
Database [23], 1995-2013. 
Table A4. Estimated coefficients from logit models of employment at a R1 or R2 university among those attaining a postdoctoral position or a tenure-track faculty appointment.

\begin{tabular}{|c|c|c|c|c|}
\hline & \multicolumn{2}{|c|}{ Main Effect } & \multicolumn{2}{|c|}{${ }^{*}$ Female } \\
\hline & $b$ & $\operatorname{se}(b)$ & $b$ & $\operatorname{se}(b)$ \\
\hline Constant & -6.693 & $(1.226)^{* * *}$ & & \\
\hline Female & -1.376 & $(0.462)^{* *}$ & & \\
\hline Year & 0.108 & $(0.024)^{* * *}$ & 0.030 & $(0.039)$ \\
\hline Year $^{2}$ & -0.003 & $(0.001) *$ & -0.002 & $(0.002)$ \\
\hline \multicolumn{5}{|l|}{ Demographic characteristics } \\
\hline Age & 0.443 & $(0.071)^{* * *}$ & & \\
\hline $\mathrm{Age}^{2}$ & -0.005 & $(0.001)^{* * *}$ & & \\
\hline U.S. citizen & -0.324 & $(0.068)^{* * *}$ & & \\
\hline \multicolumn{5}{|l|}{ Race (reference $=$ White, non-Hispanic) } \\
\hline Black, non-Hispanic & -0.297 & $(0.130)^{*}$ & & \\
\hline Asian or Pacific Islander, non-Hispanic & -0.151 & $(0.071) *$ & & \\
\hline Hispanic & -0.028 & $(0.105)$ & & \\
\hline Other, non-Hispanic & -0.356 & $(0.241)$ & & \\
\hline \multicolumn{5}{|c|}{ Degree field (reference $=$ Mathematical \& computer sciences) } \\
\hline Biological sciences & 0.303 & $(0.103)^{* *}$ & 0.072 & $(0.197)$ \\
\hline Physical, chemical and earth sciences & 0.016 & $(0.106)$ & -0.031 & $(0.212)$ \\
\hline Engineering & 0.477 & $(0.106)^{* * *}$ & -0.167 & $(0.228)$ \\
\hline \multicolumn{5}{|l|}{ Educational background } \\
\hline Years from BA to Ph.D. & -0.353 & $(0.051)^{* * *}$ & 0.188 & $(0.078)$ * \\
\hline Years from BA to Ph.D. ${ }^{2}$ & 0.010 & $(0.002)^{* * *}$ & -0.008 & $(0.003) *$ \\
\hline \multicolumn{5}{|c|}{ Carnegie class of doctorate-granting institution (reference $=$ Research University I) } \\
\hline Research University II & -0.352 & $(0.097)^{* * *}$ & 0.060 & $(0.180)$ \\
\hline Doctorate Granting I \& II & -1.146 & $(0.132)^{* * *}$ & 0.247 & $(0.217)$ \\
\hline Other & -0.851 & $(0.149)^{* * *}$ & -0.089 & $(0.231)$ \\
\hline \multicolumn{5}{|l|}{ Family Characteristics } \\
\hline \multicolumn{5}{|c|}{ Family structure at time of survey (reference $=$ No children) } \\
\hline Children aged $<2$ years & -0.076 & $(0.083)$ & 0.053 & $(0.151)$ \\
\hline Children aged $2-5$ years & -0.021 & $(0.081)$ & -0.048 & $(0.156)$ \\
\hline Children aged $6-17$ years & -0.021 & $(0.088)$ & 0.284 & $(0.177)$ \\
\hline \multicolumn{5}{|c|}{ Marital status $/$ Spouse's work status (reference $=$ Unmarried) } \\
\hline Spouse works full time & -0.068 & $(0.080)$ & 0.128 & $(0.128)$ \\
\hline Spouse works part time & 0.025 & $(0.113)$ & 0.129 & $(0.254)$ \\
\hline Spouse does not work & -0.026 & $(0.097)$ & -0.149 & $(0.200)$ \\
\hline \multicolumn{5}{|c|}{ Employment Sector (reference $=$ Postdoctoral position) } \\
\hline Faculty position, tenure-track & -0.555 & $(0.077)^{* * *}$ & -0.078 & $(0.131)$ \\
\hline \multicolumn{5}{|l|}{ Model goodness-of-fit statistics } \\
\hline Sample $(n)$ & \multicolumn{4}{|c|}{9850} \\
\hline Wald $\chi^{2}(\mathrm{df})$ & \multicolumn{4}{|c|}{$548.25(42)$} \\
\hline Pseudo $R^{2}$ & \multicolumn{4}{|c|}{0.063} \\
\hline
\end{tabular}


Table A5. Estimated coefficients from regression models of job characteristics and salary among full-time employed STEM doctorates.

\begin{tabular}{|c|c|c|c|c|c|c|c|c|c|c|}
\hline & \multicolumn{2}{|c|}{$\begin{array}{l}\text { Doctorate Required } \\
\text { in Occupation }\end{array}$} & \multicolumn{2}{|c|}{$\begin{array}{l}\text { Work Is Related to } \\
\text { Degree Field }\end{array}$} & \multicolumn{2}{|c|}{$\begin{array}{l}\text { Research Is Primary } \\
\text { Work Activity }\end{array}$} & \multicolumn{2}{|c|}{$\begin{array}{l}\text { Percent Female in } \\
\text { Occupation }\end{array}$} & \multicolumn{2}{|c|}{$\begin{array}{c}\text { Salary (among All } \\
\text { Full-Time Workers) }\end{array}$} \\
\hline & $b$ & $\operatorname{se}(b)$ & $b$ & $\operatorname{se}(b)$ & $b$ & $\operatorname{se}(b)$ & $b$ & $\operatorname{se}(b)$ & $b$ & $\operatorname{se}(b)$ \\
\hline Constant & -2.514 & $(1.222) *$ & -2.629 & $(1.058)$ * & 0.235 & (1.019) & 1.844 & $(0.514)^{* * *}$ & 10.097 & $(0.183)^{* * *}$ \\
\hline Female & -0.470 & $(0.330)$ & 0.415 & $(0.320)$ & -0.382 & $(0.322)$ & 0.557 & $(0.138)^{* * *}$ & -0.032 & $(0.054)$ \\
\hline Year & 0.012 & $(0.024)$ & 0.018 & $(0.021)$ & -0.010 & $(0.020)$ & 0.097 & $(0.009)^{* * *}$ & -0.016 & $(0.004)^{* * *}$ \\
\hline${ }^{*}$ Female & -0.054 & $(0.045)$ & -0.002 & $(0.042)$ & -0.073 & $(0.037)+$ & -0.028 & $(0.014)+$ & 0.007 & (0.007) \\
\hline Year $^{2}$ & -0.001 & $(0.001)$ & -0.001 & $(0.001)$ & 0.000 & $(0.001)$ & -0.003 & $(0.000)^{* * *}$ & 0.001 & $(0.000)^{* * *}$ \\
\hline * Female & 0.002 & $(0.002)$ & 0.000 & $(0.002)$ & 0.004 & $(0.002) *$ & 0.001 & $(0.001)$ & 0.000 & $(0.000)$ \\
\hline \multicolumn{11}{|l|}{ Demographic characteristics } \\
\hline Age & -0.035 & $(0.072)$ & -0.028 & $(0.061)$ & -0.011 & (0.059) & 0.041 & $(0.027)$ & 0.039 & $(0.011)^{* * *}$ \\
\hline Age $^{2}$ & 0.000 & $(0.001)$ & 0.001 & $(0.001)$ & 0.000 & $(0.001)$ & -0.001 & $(0.000)$ & 0.000 & $(0.000) *$ \\
\hline U.S. citizen & 0.252 & $(0.073)^{* * *}$ & 0.110 & (0.067) & -0.012 & $(0.062)$ & 0.054 & $(0.021)^{* *}$ & 0.060 & $(0.012)^{* * *}$ \\
\hline \multicolumn{11}{|l|}{ Race $($ reference $=$ White, non-Hispanic) } \\
\hline Black, non-Hispanic & 0.330 & $(0.136) *$ & -0.049 & $(0.138)$ & -0.086 & $(0.126)$ & 0.054 & $(0.050)$ & -0.043 & $(0.021)^{*}$ \\
\hline Asian or Pacific Islander, non-Hispanic & 0.235 & $(0.076)^{* *}$ & 0.046 & $(0.069)$ & 0.125 & $(0.065)+$ & 0.035 & $(0.023)$ & -0.018 & $(0.013)$ \\
\hline Hispanic & -0.085 & $(0.127)$ & 0.221 & $(0.103) *$ & 0.063 & $(0.106)$ & 0.094 & $(0.025)^{* * *}$ & -0.025 & $(0.016)$ \\
\hline Other, non-Hispanic & 0.535 & $(0.274)+$ & 0.202 & $(0.235)$ & -0.041 & $(0.213)$ & 0.032 & $(0.049)$ & 0.026 & $(0.025)$ \\
\hline \multicolumn{11}{|c|}{ Degree field (reference = Mathematical \& computer sciences) } \\
\hline Biological sciences & 1.292 & $(0.101)^{* * *}$ & -0.494 & $(0.126)^{* * *}$ & -0.941 & $(0.120)^{* * *}$ & 0.399 & $(0.042)^{* * *}$ & -0.182 & $(0.019)^{* * *}$ \\
\hline Physical, chemical and earth sciences & 0.778 & $(0.101)^{* * *}$ & -0.918 & $(0.109)^{* * *}$ & 0.292 & $(0.097)^{* *}$ & -0.011 & $(0.043)$ & -0.107 & $(0.020)^{* * *}$ \\
\hline Engineering & -1.614 & $(0.088)^{* * *}$ & -0.176 & $(0.088) *$ & 0.241 & $(0.080)^{* *}$ & -0.442 & $(0.037)^{* * *}$ & 0.003 & $(0.021)$ \\
\hline \multicolumn{11}{|l|}{ Educational background } \\
\hline Years from BA to Ph.D. & -0.113 & $(0.050) *$ & 0.032 & $(0.044)$ & 0.006 & $(0.043)$ & -0.054 & $(0.016)^{* * *}$ & -0.031 & $(0.007)^{* * *}$ \\
\hline Years from BA to Ph.D. ${ }^{2}$ & 0.004 & $(0.002) *$ & -0.001 & $(0.002)$ & 0.000 & $(0.002)$ & 0.002 & $(0.001)^{* *}$ & 0.001 & $(0.000)^{* *}$ \\
\hline \multicolumn{11}{|c|}{ Carnegie classification of doctorate-granting institution (reference $=$ Research University I) } \\
\hline Research University II & 0.187 & $(0.085) *$ & 0.000 & $(0.079)$ & 0.124 & $(0.069)+$ & -0.013 & $(0.030)$ & -0.075 & $(0.016)^{* * *}$ \\
\hline Doctorate Granting I \& II & -0.076 & $(0.096)$ & -0.029 & $(0.084)$ & 0.069 & $(0.077)$ & 0.024 & $(0.029)$ & -0.080 & $(0.020)^{* * *}$ \\
\hline Other & 0.360 & $(0.139)^{* *}$ & 0.093 & $(0.121)$ & 0.021 & $(0.135)$ & -0.068 & $(0.060)$ & -0.017 & $(0.016)$ \\
\hline \multicolumn{11}{|l|}{ Family Characteristics } \\
\hline \multicolumn{11}{|c|}{ Family structure at time of survey (reference $=$ No children) } \\
\hline Children aged $<2$ years & 0.056 & $(0.085)$ & -0.135 & $(0.071)+$ & 0.009 & $(0.073)$ & 0.039 & $(0.026)$ & -0.015 & $(0.015)$ \\
\hline${ }^{*}$ Female & -0.107 & $(0.192)$ & 0.259 & $(0.163)$ & 0.081 & $(0.162)$ & -0.082 & $(0.060)$ & 0.027 & $(0.026)$ \\
\hline Children aged $2-5$ years & 0.008 & $(0.087)$ & 0.093 & $(0.071)$ & 0.038 & $(0.071)$ & -0.011 & $(0.028)$ & 0.001 & $(0.014)$ \\
\hline${ }^{*}$ Female & -0.036 & $(0.203)$ & -0.265 & $(0.181)$ & 0.136 & $(0.166)$ & 0.019 & $(0.043)$ & 0.023 & $(0.025)$ \\
\hline
\end{tabular}


Table A5. Cont.

\begin{tabular}{|c|c|c|c|c|c|c|c|c|c|c|}
\hline & \multicolumn{2}{|c|}{$\begin{array}{l}\text { Doctorate Required } \\
\text { in Occupation }\end{array}$} & \multicolumn{2}{|c|}{$\begin{array}{l}\text { Work Is Related to } \\
\text { Degree Field }\end{array}$} & \multicolumn{2}{|c|}{$\begin{array}{c}\text { Research Is Primary } \\
\text { Work Activity }\end{array}$} & \multicolumn{2}{|c|}{$\begin{array}{l}\text { Percent Female in } \\
\text { Occupation }\end{array}$} & \multicolumn{2}{|c|}{$\begin{array}{c}\text { Salary (among All } \\
\text { Full-Time Workers) }\end{array}$} \\
\hline & $b$ & $\operatorname{se}(b)$ & $b$ & se $(b)$ & $b$ & $\operatorname{se}(b)$ & $b$ & se $(b)$ & $b$ & $\operatorname{se}(b)$ \\
\hline Children aged $6-17$ years & -0.084 & $(0.098)$ & 0.030 & $(0.083)$ & -0.130 & $(0.085)$ & -0.046 & $(0.039)$ & 0.015 & $(0.012)$ \\
\hline * Female & -0.026 & $(0.199)$ & 0.011 & $(0.139)$ & -0.308 & $(0.166)+$ & 0.044 & $(0.058)$ & -0.013 & $(0.028)$ \\
\hline \multicolumn{11}{|c|}{ Marital status/Spouse's work status (reference = Unmarried) } \\
\hline Spouse works full time & 0.130 & $(0.090)$ & 0.031 & $(0.079)$ & 0.116 & $(0.078)$ & -0.008 & $(0.030)$ & 0.025 & $(0.012)$ * \\
\hline * Female & -0.194 & $(0.151)$ & 0.093 & $(0.142)$ & -0.117 & $(0.137)$ & 0.004 & $(0.041)$ & -0.023 & $(0.021)$ \\
\hline Spouse works part time & -0.025 & $(0.125)$ & 0.287 & $(0.101) * *$ & 0.126 & $(0.107)$ & 0.019 & $(0.031)$ & 0.057 & $(0.015)^{* * *}$ \\
\hline * Female & 0.351 & $(0.271)$ & -0.004 & $(0.215)$ & 0.044 & $(0.234)$ & 0.014 & $(0.068)$ & -0.110 & $(0.041)^{* *}$ \\
\hline Spouse does not work & 0.102 & $(0.097)$ & 0.160 & $(0.083)+$ & 0.160 & $(0.084)+$ & -0.023 & $(0.033)$ & 0.065 & $(0.014)^{* * *}$ \\
\hline * Female & -0.261 & $(0.238)$ & 0.038 & $(0.181)$ & -0.339 & $(0.181)+$ & -0.027 & $(0.079)$ & -0.078 & $(0.030)^{* *}$ \\
\hline \multicolumn{11}{|l|}{ Employment characteristics } \\
\hline Hours worked & 0.027 & $(0.003)^{* * *}$ & 0.001 & $(0.003)$ & 0.000 & $(0.000)^{* * *}$ & 0.001 & $(0.001)$ & 0.002 & $(0.001)^{* *}$ \\
\hline \multicolumn{11}{|c|}{ Employment sector (reference $=$ Postdoctoral position) } \\
\hline Faculty, tenure track & & & & & & & & & 0.342 & $(0.016)^{* * *}$ \\
\hline * Female & & & & & & & & & -0.045 & $(0.026)+$ \\
\hline Faculty, not tenure track & & & & & & & & & 0.185 & $(0.022)^{* * *}$ \\
\hline${ }^{*}$ Female & & & & & & & & & -0.021 & $(0.033)$ \\
\hline Other academic or government & -0.700 & $(0.132)^{* * *}$ & 0.045 & $(0.101)$ & 0.237 & $(0.103) *$ & -0.128 & $(0.042) * *$ & 0.431 & $(0.018)^{* * *}$ \\
\hline * Female & 0.174 & $(0.229)$ & 0.122 & $(0.174)$ & 0.033 & $(0.177)$ & 0.064 & $(0.051)$ & -0.076 & $(0.032) *$ \\
\hline Business or industry & -0.422 & $(0.100)^{* * *}$ & 0.128 & $(0.080)$ & 0.523 & $(0.085)^{* * *}$ & -0.142 & $(0.028)^{* * *}$ & 0.620 & $(0.015)^{* * *}$ \\
\hline${ }^{*}$ Female & 0.573 & $(0.167)^{* * *}$ & 0.013 & $(0.152)$ & -0.033 & $(0.149)$ & -0.008 & $(0.037)$ & -0.045 & $(0.026)+$ \\
\hline Doctorate required in occupation & & & 0.009 & $(0.002)^{* * *}$ & 0.017 & $(0.002)^{* * *}$ & 0.003 & $(0.000)^{* * *}$ & 0.039 & $(0.024)+$ \\
\hline${ }^{*}$ Female & & & -0.001 & $(0.003)$ & 0.001 & $(0.003)$ & -0.001 & $(0.001) *$ & -0.023 & $(0.040)$ \\
\hline Field-occupation relatedness & 0.009 & $(0.002) * * *$ & 0.000 & $(0.000)^{* * *}$ & 0.048 & $(0.002)^{* * *}$ & 0.001 & $(0.001)$ & 0.010 & $(0.029)$ \\
\hline${ }^{*}$ Female & 0.003 & $(0.003)$ & 0.000 & $(0.000)^{* * *}$ & 0.006 & $(0.003) *$ & 0.000 & $(0.001)$ & -0.002 & $(0.042)$ \\
\hline Research is primary work activity & 0.034 & $(0.002)^{* * *}$ & 0.070 & $(0.001)^{* * *}$ & & & 0.001 & $(0.001)$ & -0.013 & $(0.035)$ \\
\hline${ }^{*}$ Female & 0.007 & $(0.003)+$ & -0.003 & $(0.003)$ & & & -0.003 & $(0.001)^{* *}$ & 0.048 & $(0.050)$ \\
\hline \multicolumn{11}{|l|}{ Model goodness-of-fit statistics } \\
\hline Sample $(n)$ & & 9199 & & 9199 & & 9199 & & 9199 & & 17,144 \\
\hline$R^{2}$ & & 0.366 & & 0.516 & & 0.388 & & 0.281 & & 0.249 \\
\hline
\end{tabular}

$+p \leq 0.10,{ }^{*} p \leq 0.05,{ }^{* *} p \leq 0.01,{ }^{* * *} p \leq 0.001$. Source: Author's calculations using data from the Survey of Doctorate Recipients [22] and the O*NET Occupational Information Network Database [23], 1995-2013. 


\section{Appendix B. Measuring the Relationship between STEM Doctoral Degrees and Occupations}

Attainment of a doctoral degree in a STEM field represents a significant investment in specialized education, and a strong commitment to a career in a STEM field. Utilizing that investment entails gaining employment in job that requires the use of the specialized knowledge and skills developed through educational experiences [28]. The underutilization of the education, skills, and expertise of women who invested in STEM fields is well-documented (for example, see [3,29-31]).

Attaining employment as a tenure-track faculty member at a research-intensive university is the ideal labor market application of a STEM doctorate because such employment fully utilizes the educational capital the STEM doctorate represents. Other types of employment vary in the degree to which they utilize doctoral-level training in a STEM field: some jobs will rival the research university faculty position in their demand for specialized skills and training, some will demand only some of the skills and specialized knowledge gained in the pursuit of a STEM doctorate, while the performance of others will demand none of those skills.

Prior research on gender differences in the utilization of science and engineering educational investments, i.e., research on gender differences in the "science pipeline," has exclusively relied on a researcher-imposed operationalization of educational utilization [3]. In this approach, researchers classify a set of occupations as those that comprise the STEM labor market, and employment in one of these occupations is defined as the utilization of STEM education. The researcher-imposed classification may be based on any combination of independent judgment, the conventions of prior research, or classification schemes used by benchmarking entities [6,7].

Although the researcher-defined approach is reasonable, it has significant limitations which may produce biased estimates of the degree to which STEM doctorates utilize their education in the labor market, i.e., the degree to which they stay in the "pipeline." First, it relies on the judgment of the researcher, rather than on the assessment of the individuals whose education-work transition is being observed or on an empirical method of measuring the substantive consistency of education-occupation pairing. As such, it is likely to be strongly influenced by the something as relatively capricious as the labeling of the categories in the classification scheme. The researcher-defined approach also ignores the fact that occupational categories combine jobs that may differ in the degree to which they are related to a STEM degree. This variability cannot be reflected in the dichotomous nature of the researcher-defined operationalization, nor can the education-occupations "linkages" identified by a binary indicator variable capture the relative strength of education-occupation connections [28].

To obtain unbiased estimates of gender differences in the attainment of employment that utilizes STEM education, I operationalize education-occupation relatedness by measuring the degree to which an occupation requires doctorate-level education, demands research skills, and is substantively related to their degree field. The level of education required for employment in a given job is a basic measure of whether one's education will be utilized on the job. For doctorates, the extent to which a doctoral degree is required by the jobs in an occupational category is a first-order measure of whether an occupation is commensurate with their educational investment. Second, since doctoral-level education in STEM fields is devoted to the training of research skills, I use the extent to which research is a primary work activity to capture another dimension of education-occupation relatedness. Third, I use the degree to which an occupation is related to various STEM fields as a measure of the substantive education-occupation relatedness. Using these measures of educational utilization to track employment outcomes may provide a new understanding of where in the labor market the science pipeline leads and to what extent those pathways differ by gender.

\section{References}

1. National Science Foundation. Women, Minorities, and Persons with Disabilities in Science and Engineering: 2015. Special Report NSF 15-311. Arlington: National Science Foundation, 2015. Available online: http: / /www.nsf.gov/statistics/wmpd/ (accessed on 29 August 2016).

2. National Science Board. Science and Engineering Indicators 2016. Arlington: National Science Foundation, 2016. 
3. Yu Xie, and Kimberlee A. Shauman. Women in Science: Career Processes and Outcomes. Cambridge: Harvard University Press, 2003.

4. National Research Council, Policy and Global Affairs, Division of Behavioral and Social Sciences and Education, Committee on Women in Science, Engineering, and Medicine, Committee on National Statistics, and Committee on Gender Differences in Careers of Science, Engineering, and Mathematics Faculty. Gender Differences at Critical Transitions in the Careers of Science, Engineering, and Mathematics Faculty. Washington: National Academies Press, 2010.

5. Committee on Gender Differences in the Careers of Science, Engineering, and Mathematics Faculty, Committee on Women in Science, and Medicine, Policy and Global Affairs, and Committee on National Statistics Division of Behavioral and Social Sciences and Education. Gender Differences at Critical Transitions in the Careers of Science, Engineering, and Mathematics Faculty. Washington: The National Academies Press, 2009.

6. National Science Foundation. Science and Engineering Indicators 2012. Arlington: National Center for Science and Engineering Statistics, 2012.

7. National Science Foundation. Science and Engineering Indicators 2014. Arlington: National Center for Science and Engineering Statistics, 2014.

8. Silvia Knobloch-Westerwick, Carroll J. Glynn, and Michael Huge. “The Matilda Effect in Science Communication: An Experiment on Gender Bias in Publication Quality Perceptions and Collaboration Interest." Science Communication 35 (2013): 603-25. [CrossRef]

9. Corinne A. Moss-Racusin, John F. Dovidio, Victoria L. Brescoll, Mark J. Grahama, and Jo Handelsman. "Science faculty's subtle gender biases favor male students." Proceedings of the National Academy of Sciences 109 (2012): 16474-79. [CrossRef] [PubMed]

10. Ernesto Reuben, Paola Sapienza, and Luigi Zingales. "How stereotypes impair women's careers in science." Proceedings of the National Academy of Sciences 111 (2014): 4403-8. [CrossRef] [PubMed]

11. Shelley Correll, Stephan Benard, and In Paik. "Getting a Job: Is There a Motherhood Penalty?" The American Journal of Sociology 112 (2007): 1297-338. [CrossRef]

12. Erin A. Cech, and Mary Blair-Loy. "Consequences of Flexibility Stigma among Academic Scientists and Engineers." Work and Occupations 41 (2014): 86-110. [CrossRef]

13. Mary Frank Fox. "Women, Science, and Academia: Graduate Education and Careers." Gender E Society 15 (2001): 654-66.

14. Mary Frank Fox, and Paula E. Stephan. "Careers of young scientists: Preferences, prospects and realities by gender and field." Social Studies of Science 31 (2001): 109-22. [CrossRef]

15. Anna L. W. Sears. "Image problems deplete the number of women in academic applicant pools." Journal of Women and Minorities in Science and Engineering 9 (2003): 169-81. [CrossRef]

16. Donna K. Ginther. "Is MIT the Exception? Gender Pay Differentials in Academic Science." Bulletin of Science, Technology, and Society 23 (2003): 21-26. [CrossRef]

17. Donna K. Ginther. "Why Women Earn Less: Economic Epxplanations for the Gender Salary Gap in Science." AWIS Magazine 33 (2004): 6-10.

18. Donna K. Ginther, and Shulamit Kahn. “Does Science Promote Women? Evidence from Academia 1973-2001." In Science and Engineering Careers in the United States. Edited by Richard B. Freeman and Daniel L. Goroff. Chicago: University of Chicago Press for NBER Science Engineering Workforce Project, 2009.

19. Committee on Science, Engineering, and Public Policy. Enhancing the Postdoctoral Experience for Scientists and Engineers. Washington: National Academy Press, 2000.

20. Paula Stephan, and Jennifer Ma. "The increased frequency and duration of the postdoctorate career stage." The American Economic Review 95 (2005): 71-75. [CrossRef]

21. Diane H. Felmlee. “Causes and Consequences of Women's Employment Discontinuity, 1967-1973.” Work and Occupations 22 (1995): 167-87. [CrossRef]

22. National Center for Science and Engineering Statistics. Survey of Doctorate Recipients, Restricted-Use Microdata Files. Arlington: National Science Foundation, 1995-2013.

23. National Center for O*NET Development. “O*NET OnLine." Available online: https://www.onetonline.org/ (accessed on 22 May 2016).

24. Ron Boese, Phil Lewis, Pam Frugoli, and Karen Litwin. Summary of O*NET 4.0 Content Model and Database. Raleigh: National Center for O*NET Development, 2001. 
25. Paul D. Allison, and J. Scott Long. “Departmental Effects on Scientific Productivity.” American Sociological Review 55 (1990): 469-78. [CrossRef]

26. J. Scott Long, Paul D. Allison, and Robert McGinnis. "Rank Advancement in Academic Careers: Sex Differences and the Effects of Productivity." American Sociological Review 58 (1993): 703-22. [CrossRef]

27. Richard Williams. "Using the Margins Command to Estimate and Interpret Adjusted Predictions and Marginal Effects." The Stata Journal 12 (2012): 308-31.

28. Kimberlee A. Shauman. "Are There Sex Differences in the Utilization of Educational Capital Among College-Educated Workers?" Social Science Research 38 (2009): 535-71. [CrossRef]

29. Anne E. Preston. Leaving Science: Occupational Exit from Scientific Careers. New York: Russell Sage Foundation, 2004.

30. Gerhard Sonnert, and Gerald Holton. "Career Patterns of Women and Men in the Sciences." American Scientist 84 (1996): 63-71.

31. Virginia Valian. Why So Slow? The Advancement of Women. Cambridge: The MIT Press, 1999.

(C) 2017 by the author. Licensee MDPI, Basel, Switzerland. This article is an open access article distributed under the terms and conditions of the Creative Commons Attribution (CC BY) license (http:/ / creativecommons.org/licenses/by/4.0/). 